\title{
Reconstruction and analysis of the Chukchi Sea circulation in 1990-1991
}

\author{
G. Panteleev, ${ }^{1}$ D. A. Nechaev, ${ }^{2}$ A. Proshutinsky, ${ }^{3}$ R. Woodgate, ${ }^{4}$ and J. Zhang ${ }^{4}$ \\ Received 18 April 2009; revised 6 November 2009; accepted 1 February 2010; published 24 August 2010.
}

[1] The Chukchi Sea (CS) circulation reconstructed for September 1990 to October 1991 from sea ice and ocean data is presented and analyzed. The core of the observational data used in this study comprises the records from 12 moorings deployed in 1990 and 1991 in U.S. and Russian waters and two hydrographic surveys conducted in the region in the fall of 1990 and 1991. The observations are processed by a two-step data assimilation procedure involving the Pan-Arctic Ice-Ocean Modeling and Assimilation System (employing a nudging algorithm for sea ice data assimilation) and the Semiimplicit Ocean Model [utilizing a conventional four-dimensional variational (4D-var) assimilation technique]. The reconstructed CS circulation is studied to identify pathways and assess residence times of Pacific water in the region; quantify the balances of volume, freshwater, and heat content; and determine the leading dynamical factors configuring the CS circulation. It is found that in 1990-1991 (high AO index and a cyclonic circulation regime) Pacific water transiting the CS toward the Canada basin followed two major pathways, namely via Herald Canyon (Herald branch of circulation, $0.23 \mathrm{~Sv}$ ) and between Herald Shoal and Cape Lisburne (central branch of circulation and Alaskan Coastal Current, $0.32 \mathrm{~Sv}$ ). The annual mean flow through Long Strait was negligible $(0.01 \mathrm{~Sv})$. Typical residence time of Pacific water in the region varied between 150 days for waters entering the CS in September and 270 days for waters entering in February/March. Momentum balance analysis reveals that geostrophic balance between barotropic pressure gradient and Coriolis force dominated for most of the year. Baroclinic effects were important for circulation only in the regions with large horizontal salinity gradients associated with the fresh Alaskan and Siberian coastal currents and the Cape Lisburne and Great Siberian polynyas. In the polynyas, the baroclinic effects were due to strong salinification and convection processes associated with sea ice formation.

Citation: Panteleev, G., D. A. Nechaev, A. Proshutinsky, R. Woodgate, and J. Zhang (2010), Reconstruction and analysis of the Chukchi Sea circulation in 1990-1991, J. Geophys. Res., 115, C08023, doi:10.1029/2009JC005453.

\section{Introduction}

[2] Water circulation in the shallow (mean depth is approximately $50 \mathrm{~m}$ ) Chukchi Sea (hereafter CS) (Figure 1) is regulated externally by sea level gradient between the Pacific and Atlantic oceans and by wind [e.g., Shtokman, 1957; Coachman and Aagaard, 1966]. The estimates of this sea level gradient vary from $1.0 \times 10^{-6}[$ Shtokman, 1957 ; Gudkovich, 1961; Coachman et al., 1975; Coachman and

\footnotetext{
${ }^{1}$ International Arctic Research Center, University of Alaska Fairbanks, Fairbanks, Alaska, USA.

${ }^{2}$ Department of Marine Science, University of Southern Mississippi, Stennis Space Center, Hattiesburg, Mississippi, USA.

${ }^{3}$ Woods Hole Oceanographic Institution, Woods Hole, Massachusetts, USA.

${ }^{4}$ Applied Physics Laboratory, University of Washington, Seattle, Washington, USA.

Copyright 2010 by the American Geophysical Union. 0148-0227/10/2009JC005453
}

Aagaard, 1966] to $1.3 \times 10^{-6}$, [Proshutinsky, 1986]. It is generally hypothesized that this gradient is of steric origin [Coachman et al., 1975; Stigebrandt, 1984] due to different evaporation and precipitation rates in the Pacific Ocean (precipitation prevails over evaporation, and sea level is elevated) and the Atlantic Ocean (evaporation dominates precipitation and sea level is reduced). This sea level gradient is speculated to drive the mean northward flow of approximately $0.8-1.0 \mathrm{~Sv}\left(1 \mathrm{~Sv}=10^{6} \mathrm{~m}^{3} \mathrm{~s}^{-1}\right)$ from the Pacific Ocean through Bering Strait across the CS toward the Atlantic Ocean. Wind significantly modifies the Bering Strait inflow at time scales from synoptic to interannual, sometimes blocking it completely or even reversing it [see Proshutinsky, 1986; Aagaard et al., 1985; Roach et al., 1995; Woodgate et al., 2005a, and discussion therein]. This basic understanding of the CS circulation dynamics has been improved since earlier studies of the 1950s and 1970s [Shtokman, 1957; Gudkovich, 1961, 1962; Coachman et al., 1975] by both observational [Weingartner et al., 2005; Aagaard et al., 


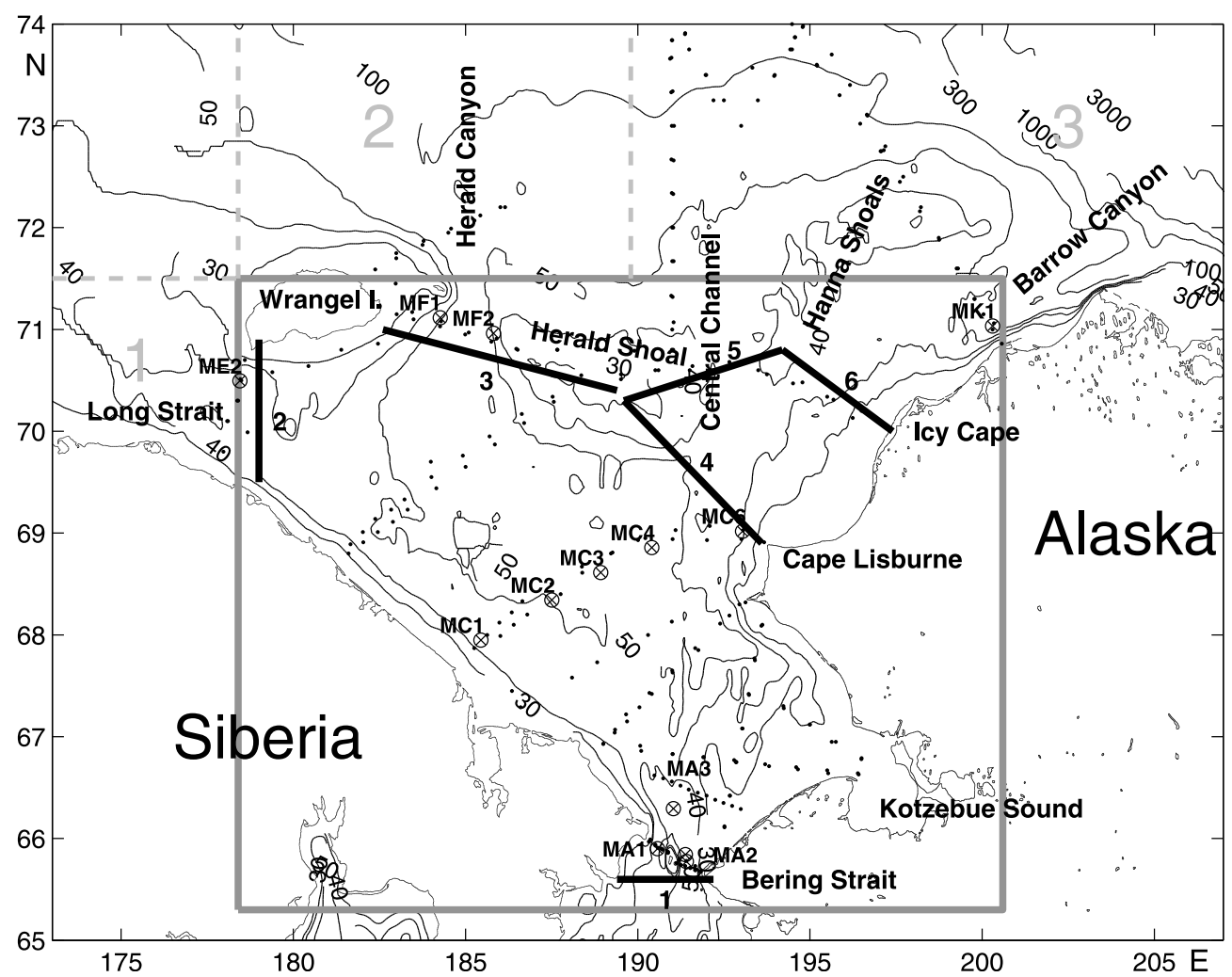

Figure 1. Bottom topography in the Chukchi Sea. 1990-1991 mooring locations are depicted as circles with crosses. Sections with CTD stations are shown as dots. Notations MA1-MA3, MC1-MC4, MC6, ME2, MF1, MF2, and MK1 designate the corresponding moorings [see Woodgate et al., 2005a]. (1)(5) depict sections crossing the Bering Strait, Long Strait, Herald Canyon, Herald Shoal-Cape Lisburne, Herald Shoal-Hanna Shoal, and Hanna Shoal-Icy Cape, respectively. The thick gray line outlines the domain of the SIOM. Gray numbers designate three subdomains where the particle study was carried out.

1985; Woodgate et al., 2005a] and modeling studies [Proshutinsky, 1986; Overland and Roach, 1987; Spaulding et al., 1987; Nihoul et al., 1993; Proshutinsky et al., 1995; Winsor and Chapman, 2004; Spall, 2007]. There are also other physical factors that influence the CS circulation. The bottom topography is likely responsible for the existence of the three branches of Pacific water transiting the CS region, namely, Alaskan Coastal Current, Central, and Herald outflows [Coachman et al., 1975; Coachman and Aagaard, 1966; Weingartner et al., 1998; Woodgate et al., 2005a] with synoptic and seasonal variability being regulated by the wind and sea ice conditions. The sea ice could be considered as both an external (when it is advected into the region from the Bering Sea, Beaufort, or the East Siberian Sea) and/or internal system parameter (when it is generated in the CS during winter). Land-fast ice is a good example of how this internal parameter may influence the CS circulation by inhibiting transfer of wind stress at the ocean surface and generating upwelling or downwelling along the land-fast ice edge [Carmack and Chapman, 2003]. On the other hand, the local sea ice is influenced significantly by the inflow from the Bering Sea because the Bering seawater brings heat that in the annual average is enough to melt approximately $30 \mathrm{~cm}$ of the entire arctic winter sea ice area [Fedorova and Yankina, 1963]. Another example of the potential importance of Bering seawater heat advected to the CS was demonstrated by Woodgate et al. [2006], who showed that the increase alone of Bering Strait heat input between 2001 and 2004 could have melted $640,000 \mathrm{~km}^{2}$ of $1 \mathrm{~m}$ thick ice. The Pacific water inflow also brings a significant amount of freshwater to the Arctic Ocean because these waters are less saline ( 32.5) [Woodgate et al., 2005b] than the mean Arctic Ocean water salinity (34.8) [Aagaard and Carmack, 1989]. The freshwater flux (calculated relative to water salinity $34.8)$ to the Arctic Ocean via the Bering Strait is approximately $2500 \mathrm{~km}^{3} \mathrm{yr}^{-1}$, and is comparable with the annual river runoff to the Arctic Ocean [Woodgate and Aagaard, 2005b; Serreze et al., 2006].

[3] In addition to the water exchange with the Pacific Ocean, the CS interacts with the East Siberian Sea via Long Strait. The dynamics of these interactions is not well observed. Nikiforov and Shpayher [1980] based on the analysis of geochemical tracers (silicate, oxygen, salinity) have shown that the water exchange between the East Siberian Sea and CS via Long Strait depends on the atmospheric circulation regime. During an anticyclonic regime, Pacific water under the influence of wind forcing is able to occupy significant areas of the East Siberian Sea. In the years of a cyclonic regime, wind blocks the flow of Pacific waters to the East Siberian Sea and a flow from the East Siberian Sea to the CS has to be observed.

[4] Arctic navigation manuals and reference books [e.g., Pavlov et al., 1996; Proshutinsky et al., 1995] describe a flow called the Siberian Coastal Current (SCC), which enters 
the CS via Long Strait and turns offshore at approximately $175^{\circ} \mathrm{W}$. Before the late $1990 \mathrm{~s}$, this current had never been measured or observed instrumentally, and knowledge of its existence was based only on some observations made by Sverdrup [1929] and observations of the eastward sea ice drift made from coastal stations. Traditionally, it was assumed that SCC was forced by buoyancy flux originating from Siberian river runoff (Kolyma and Lena rivers). Recently, however, Weingartner et al. [1999] and Münchow et al. [1999] observed several events when the SCC flowed westward under the forcing of unusual southwestward winds. This agrees with modeling studies that show that some Pacific water penetrates into the East Siberian Sea under certain forcing conditions [see Proshutinsky, 1986; Winsor and Chapman, 2004].

[5] The number of oceanographic observations in the CS has increased dramatically during the last two decades. The observations comprise conventional water temperature and salinity (hereafter T\&S) data and a large number of highquality velocity time series from moorings, mooring-based and ship-based acoustic Doppler current profilers (ADCPs), and surface drifter data. Most of these data sets have been analyzed separately in a number of publications that clarified different aspects of the CS dynamics. For example, velocity measurements in the Bering Strait have been conducted almost continuously since the beginning of the 1990s, providing estimates of water exchange between the Pacific and Arctic oceans [Woodgate et al., 2005b, 2006]. Münchow et al. [1999] analyzed ADCP and drifter data collected in the western part of the CS and unexpectedly revealed a persistent westward flow along the Siberian coast in August-October 1995.

[6] The most comprehensive observational program in the CS was conducted in 1990-1991. The observational data set included 12 moorings deployed both in U.S. and Russian waters and two hydrographic surveys in the fall of 1990 and 1991. Woodgate et al. [2005a] based on water temperature, salinity, and velocity observations collected in 1990-1991 have investigated variability of the CS circulation at different time scales. Some results of this work will be discussed in this paper in comparison with our modeling results.

[7] The major goal of the current paper is to reconstruct the CS circulation by combining observational data with numerical modeling and employing the four-dimensional variational (4D-var) data assimilation technique. This method [e.g., Le Dimet and Talagrand, 1986] provides an efficient way of reconstructing circulation in any particular region via an optimization of both the open boundary conditions and the model solution with respect to the available observational data. Over the two last decades, this method has proved to be a useful and efficient tool for the study of ocean circulation [e.g., Wunsch, 1996; Stammer et al., 2002; Awaji et al., 2003]. This approach closes the gap between circulation studies relying heavily on observations (such as the dynamical method, water mass analysis, and diagnostic modeling) and methods based on dynamical constraints alone (such as model simulations). The principal advantage of this approach is its ability to take into account practically all kinds of observational data together with the corresponding statistical information such as estimates of the data error variance. There are also several problems that complicate the application of 4D-var data assimilation in practice. The major problem is related to the significant gaps in the spatial and temporal ocean data coverage. The ocean, especially in the polar regions, is highly undersampled if the number of available observations is compared to the number of degrees of freedom of a realistic ocean circulation model. Another common problem of 4D-var data assimilation methods stems from the strong nonlinearity of oceanic and, in particular, sea ice processes that are taken into account in the oceanic and sea ice models. Such nonlinearity reduces the time interval of applicability of the tangent linear and adjoint models involved in the 4D-var technique and may significantly slow down convergence of the minimization algorithm required by the $4 \mathrm{D}$-var approach.

[8] In the current study, we utilize a two-step data assimilation technique involving nudging type assimilation of the sea ice data and 4D-var assimilation of oceanic observations in order to resolve the problems identified above. The numerical models, statistical hypotheses, and specific details of the data and data assimilation procedures are outlined in section 2 . In section 3 , the major results of the reconstruction of the CS circulation are presented. Summary and conclusions are provided in section 4 .

\section{Models and Data Assimilation Algorithms}

[9] The CS is covered by sea ice almost 8 months a year. Ideally, the data assimilation procedure should take into account ice-ocean interactions and the data assimilation algorithm should be designed for a sea ice-ocean coupled model system. Development of a 4D-var data assimilation procedure for such a coupled ice-ocean system is not straightforward. Strong nonlinearity of the sea ice dynamics complicates development of a stable adjoint model and results in low controllability of the sea ice model. Effectively, dynamical complexity of this coupled ice-ocean system may limit applicability of 4D-var data assimilation methods for long time period integration intervals. Thus, to avoid such technical problems, we use a set of simplified suboptimal data assimilation methods described below.

\subsection{Pan-Arctic Ice-Ocean Modeling and Assimilation System}

[10] The sea ice data are assimilated by the Pan-Arctic IceOcean Modeling and Assimilation System (PIOMAS) developed at the Polar Science Center, University of Washington [see Zhang and Rothrock, 2001, 2003, 2005]. The PIOMAS is a coupled parallel ocean and sea ice model with capabilities of assimilating sea ice concentration. It consists of the thickness and enthalpy distribution (TED) sea ice model developed by Zhang and Rothrock [2001, 2003] and the Parallel Ocean Program (POP) developed at the Los Alamos National Laboratory. The TED sea ice model is a dynamic thermodynamic model that also explicitly simulates sea ice ridging. It has 12 categories, each for ice thickness, ice enthalpy, and snow. The model employs a teardrop viscousplastic ice rheology that determines the relationship between ice internal stress and ice deformation [see Zhang and Rothrock, 2005], a mechanical redistribution function that determines ice ridging [see Thorndike et al., 1975; Rothrock, 1979; Hibler, 1980] and an efficient numerical method to solve the ice motion equation [Zhang and Hibler, 1997]. 
Assimilation of sea ice concentration data from satellites in PIOMAS is based on an assimilation procedure [Lindsay and Zhang, 2006] that "nudges" the model estimate of ice concentration toward the observed concentration in a manner that emphasizes the ice extent and minimizes the effect of observational errors in the interior of the ice pack. This is a relatively simple yet effective assimilation scheme that is computationally affordable for long-term integrations and experiments. In addition to improving the simulated ice edge, comparisons to observed ice thickness measurements in the Arctic indicate that the assimilation of ice data also improves the simulated ice motion and thickness.

\subsection{Semi-Implicit Ocean Model}

[11] Oceanographic observations are assimilated into the Semi-implicit Ocean Model (SIOM) data assimilation system. SIOM is a modification of the $\mathrm{C}$ grid, $z$ coordinate OGCM (Ocean Global Circulation Model) developed in Laboratoire d'Oceanographie Dynamique et de Climatologie [Madec et al., 1999]. This model was designed specifically for the implementation of 4D-var methods into regional models controlled by fluxes at the open model boundaries and sea surface. The model is semi-implicit both for barotropic and baroclinic modes, permitting simulations with relatively large time steps of approximately 0.1 day [Nechaev et al., 2005; Panteleev et al., 2006a, 2006b]. The tangent linear model was obtained by direct differentiation of the forward model code. The adjoint code of the model was built analytically by transposition of the operator of the tangent linear model, linearized in the vicinity of the given solution of the forward model [Wunsch, 1996]. The details of the SIOM numerical scheme can be found in the work of Nechaev et al. [2005].

\subsection{Model Configurations and Assimilating System Coupling}

[12] The PIOMAS is configured to cover the region north of $43^{\circ} \mathrm{N}$ with a mean horizontal resolution of approximately $22 \mathrm{~km}$. The model is one-way nested to a Global Ice-Ocean Modeling and Assimilation System, which consists of similar sea ice and ocean models [Zhang, 2005]. The SIOM was configured for the domain shown in Figure 1. The choice of the domain boundary is dictated by mooring locations; we avoided regions with insufficient data coverage (for example, along the continental slope). The SIOM's grid has a horizontal resolution of $10 \mathrm{~km}$ with 15 unequally spaced vertical levels ranging between $2.5 \mathrm{~m}$ near surface and 10 $20 \mathrm{~m}$ near the oceanic bottom. The time step of the model is $2.4 \mathrm{~h}$. The original version of SIOM does not have a sea ice model but is able to assimilate the momentum, heat, and salt fluxes between ice and ocean. We use this possibility in implementation of a two-step data assimilation algorithm to avoid problems associated with the strong nonlinearity of sea ice dynamics discussed above.

[13] At the first step of the algorithm, we run PIOMAS for the entire Arctic Ocean domain, and PIOMAS assimilates sea ice concentration data and simulates sea ice and water dynamics. At the second step, the SIOM assimilates external forcing provided by PIOMAS output over the SIOM domain (surface heat, salt, and momentum fluxes) and all available hydrographic data (water temperature, salinity, velocity) employing a conventional 4D-var data assimilation proce- dure that ensures dynamical consistency of the ocean model solution [Nechaev et al., 2005; Panteleev et al., 2006a, 2006b]. To reduce the number of "unknowns" in the 4D-var data assimilation procedure, the time variability of the SIOM forcing fields and the functions specifying the open boundary conditions is approximated by piecewise linear continuous functions of time on 3 day intervals. The final product of the data assimilation system includes reconstructed patterns of circulation and water T\&S fields stored at the end of every seventh day of the SIOM integration.

\subsection{Data and Data Sources}

[14] Several types of data are needed for the reconstruction of circulation: (a) in situ observations to be assimilated by the PIOMAS-SIOM system, (b) atmospheric and boundary data to force PIOMAS and SIOM models, and (c) climatological information required to regularize the data assimilation problem by filling the gaps in the in situ observations.

[15] In addition, the reconstruction procedure needs specification of error statistics for all assimilated data. The errors in the independent observations are characterized by the data error variances and assumed to be uncorrelated. It is important to note that the data error variances utilized in the data assimilation procedure are not only related to the instrumental errors during observations. The required error estimates also depend on the preprocessing procedures (e.g., time filtering or interpolation) and/or discrepancies between the observed and modeled temporal and spatial scales of the circulation.

\subsubsection{In Situ Data}

[16] These data include direct observations of oceanic and sea ice conditions in 1990-1991. A set of 12 moorings, each carrying an Aanderaa Recording Current Meter (RCM) and a Seabird SeaCat (SBE) approximately $10 \mathrm{~m}$ above the seafloor, was deployed in the CS in September 1990 and measured oceanic parameters (ocean currents, water temperature, and salinity) until September 1991 (Figure 1). A detailed description of the observational data and data processing procedures can be found in Woodgate et al. [2005c]. In order to remove high-frequency variability for our analysis, the observed time series were filtered with a 5 day cutoff low-pass Butterworth filter. The estimated velocity and $\mathrm{T} \& \mathrm{~S}$ variances range (depending on region) within 3.0 $7.0 \mathrm{~cm} \mathrm{~s}^{-1}, 0.1^{\circ} \mathrm{C}-0.3^{\circ} \mathrm{C}$, and $0.05-0.1$ salinity units, respectively.

[17] The T\&S data from 153 CTD profiles (hydrographic surveys of RV "Khromov" and "Surveyor" in SeptemberOctober 1990, Figure 1) were used by SIOM to assimilate observed vertical water temperature and salinity distributions at the closest to observational sites model grid points. These data were also used as the first guess initial T\&S conditions for SIOM initialization. For this purpose, the data were optimally interpolated onto the SIOM grid. The estimated $\mathrm{T} \& \mathrm{~S}$ variances vary from region to region within limits of $0.1^{\circ} \mathrm{C}-0.3^{\circ} \mathrm{C}$ and $0.05-0.10$ salinity units, respectively.

\subsubsection{Forcing Data}

[18] Near surface wind fields, heat and salt fluxes data for assimilation procedures are taken from National Centers for Environmental Prediction (NCEP) reanalysis (www.cdc. noaa.gov/cdc/data.ncep.reanalysis.derived.html).

[19] These data were found to be very smooth for the CS region. The error analysis of the NCEP/National Center for 


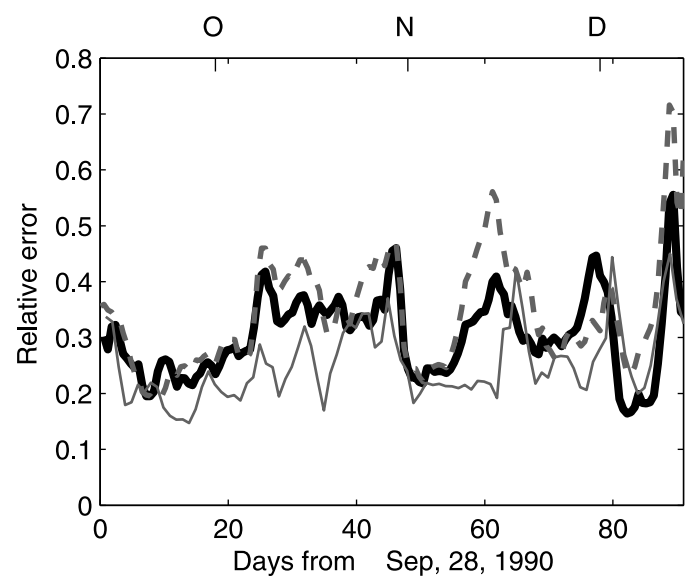

Figure 2. Mean relative velocity error in the optimized SIOM solution. Dashed line, error in the solution obtained by assimilating ocean velocity and $\mathrm{T} / \mathrm{S}$ data and using the NCEP/NCAR surface fluxes; solid thick line, error in the solution obtained by assimilating ocean velocity and T\&S data and using the surface fluxes derived from the sea ice assimilating PIOMAS run; solid thin line, error in the case of assimilating only velocity data and surface momentum fluxes derived from the sea ice assimilating PIOMAS run into barotropic SIOM.

Atmospheric Research (NCAR) data was performed by Ladd and Bond [2002] for the North Pacific Ocean and for the Bering Sea, and we assume that for the CS the NCEP/ NCAR error variances can be similar or even larger than for the Bering Sea because of sparse observations in this region. In this situation, to allow for the adjustment of the spatial details in the model forcing, we used wind stress, heat, and salt flux data with relatively high error variances (up to $40 \%$ of their spatial and temporal variability in the CS). Meteorological data were filtered with the 5-day cutoff filter in order to remove high-frequency variability and make the data consistent with the mooring velocity data.

[20] NCEP/NCAR daily sea surface temperature (SST) data were linearly interpolated onto the model grid and filtered with the 5-day cutoff filter similar to the procedure described above. A comparison of the NCAR/NCEP SSTs and in situ historical surface temperature observations (see description below) in the CS revealed significant differences with a maximum error of $5^{\circ} \mathrm{C}-6^{\circ} \mathrm{C}$ in Kotzebue Sound in late summer. Thus, the SST data were used with a very large error variance of $0.5^{\circ} \mathrm{C}-5.0^{\circ} \mathrm{C}$, with the smallest error variance values being applied in the northern part of the CS.

[21] The sea ice parameters assimilated by PIOMAS for the entire Arctic Ocean model domain included the Special Sensor Microwave/Imager (SSMI) ice concentration obtained from the Hadley Center (http://hadobs.metoffice.com/ hadisst/). In order to validate PIOMAS results, raw buoy displacement data from the International Arctic Buoy Program (IABP) and satellite-derived ice velocities based on images from the SSMI, available from the National Snow and Ice Data Center (NSIDC), were used as well.

\subsubsection{Climatological Information}

[22] The climatological information about the CS hydrography was derived from a data base (courtesy of Vladimir
Luchin) of the Far Eastern Branch of Russian Academy of Science. This data base includes bottle, mechanical bathythermograph, high-resolution CTD, and expendable bathythermograph data collected in the CS by U.S., Japanese, and Russian expeditions between 1990 and 2005. Mean monthly gridded T\&S fields for the CS were obtained by linear interpolation of observational data into the SIOM model grid. These data are used as climatology for the CS for the 4D-var analysis. The estimated T\&S variances change spatially and temporarily within $0.2^{\circ} \mathrm{C}-0.8^{\circ} \mathrm{C}$ and $0.1-0.3$ salinity units, respectively.

\subsection{Tests of Model Applicability}

[23] In order to assess the applicability of the approach described above, we performed two numerical experiments. First, we reconstructed circulation in the CS for the period of 3 months starting from 28 September 1990 and assimilated the ocean and meteorological data described above. The data were assimilated directly into SIOM employing the 4D-var data assimilation procedure but using NCEP surface forcing. In the second experiment, we reconstructed circulation in the same region by (1) assimilating sea ice data into PIOMAS and (2) assimilating PIOMAS output and ocean data into the SIOM. Errors $\left(\varepsilon_{\mathrm{u}}\right)$ showing results of these experiments were evaluated as follows:

$$
\varepsilon_{\mathrm{u}}=\left(\sum\left|\boldsymbol{u}_{\mathrm{m}}-\boldsymbol{u}_{\mathrm{d}}\right|^{2} / \sum\left|\boldsymbol{u}_{\mathrm{d}}\right|^{2}\right)^{1 / 2},
$$

where $\boldsymbol{u}_{\mathrm{d}}$ is observed velocity vector from observations at mooring and $\boldsymbol{u}_{\mathrm{m}}$ is its model counterpart from model results. Summation was performed over all velocity data.

[24] The relative velocity errors in the two control experiments (Figure 2) do not differ significantly for the first 2 months of the reconstruction. Note that these first 2 months were characterized by ice-free conditions in the region under consideration.

[25] Also, the model solutions forced with NCEP/NCAR and PIOMAS surface stresses are close to each other because the PIOMAS was also forced by the NCEP/NCAR atmospheric fluxes, and during the periods of low sea ice concentration, the PIOMAS did not modify these fluxes. However, starting at the end of November 1990 (50th day of integration), the solutions of the two control experiments diverge. During this period, the relative error, $\varepsilon_{\mathrm{u}}$ for the experiment with NCEP/NCAR atmospheric forcing increases up to $0.60-0.75$, while in the case of PIOMAS forcing, this error is smaller, i.e., 0.50. These results demonstrate that the assimilation of PIOMAS-derived forcing into SIOM improves reconstructed results and confirms applicability of the proposed data assimilation procedure for the CS region.

[26] For computational reasons, we did not extend the comparison over a larger period but instead focused our efforts on reconstructing the circulation in the CS during a 1 year period using the data assimilation approach described above. The data assimilation started on 28 September 1990. The optimized control vector of the SIOM included initial, open boundary, and surface boundary conditions for momentum and heat/salt fluxes. In order to make the minimization problem computationally feasible, all functions prescribing open boundary and surface conditions were 

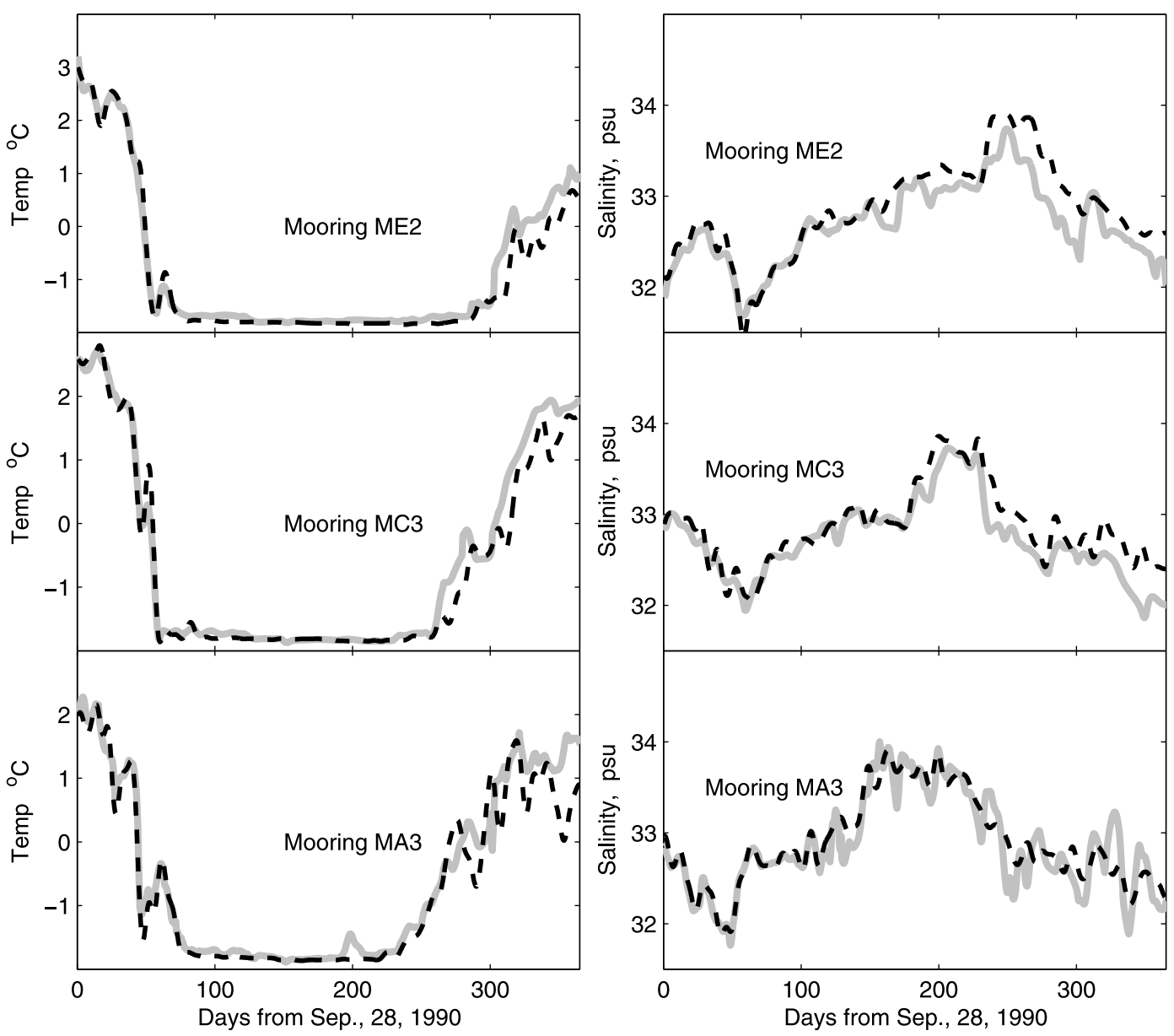

Figure 3. Reconstructed (gray) and observed (dashed) (left) temperature and (right) salinity at moorings MA3, MC3, and ME2, respectively.

approximated in time by piecewise linear continuous functions on 3 day intervals. The resulting control vector includes 2,660,158 elements. In order to accelerate the minimization procedure, we optimized the SIOM solution for a period of one year through the solution of several consecutive minimizations for periods of 2-4 months. These periods of "small" minimization problems partly overlapped with each other. For the first period, we optimized both initial and boundary conditions. Starting from the second small period, only boundary and surface conditions were adjusted, ensuring the continuity of the SIOM solution on the entire time period. Finally, the optimization of the control vector on the whole reconstruction period was conducted. The time averaged relative model data velocity error of the reconstructed circulation is approximately $\varepsilon_{\mathrm{u}}=0.32$, with minimum (maximum) values of $0.10(0.60)$.

[27] In order to estimate the roles of baroclinic factors in the CS circulation, we have conducted one additional test experiment with a barotropic SIOM employing assimilation of the data relevant to the barotropic calculations (the velocity data). Interestingly, the disagreement between observed and reconstructed velocities in the baroctropic model case was smaller (see Figure 2). The mean model data error became 0.25 instead of 0.30 for the baroclinic test with PIOMAS forcing. We think that this is because in the bar- oclinic case the dimension of the minimization problem and its nonlinearity are significantly larger than in the barotropic model, while T\&S data impose additional constraints. We also found that in the barotropic case the circulation differs from the baroclinic case in several regions. For example, in the Long Strait the barotropic solution does not reproduce the Siberian Coastal Current. The barotropic water transports through domain open boundaries differ from the water transports reproduced by the baroclinic SIOM.

[28] This test indicates that an analysis of the CS circulation based on a barotropic model can result in some deficiencies in water circulation in this region.

\section{Reconstruction Results}

[29] There are three clear periods with different behavior of the model data T\&S differences (Figure 3). The first period extends for an initial 100 days of the reconstruction. During this period, both model T\&S are in almost perfect agreement with observations. As it is described above, there were more than 150 CTD stations during this initial period (Figure 1). The significant volume of CTD and velocity data allows for accurate reconstruction of initial and boundary conditions. Also note that the strong topographic steering 
provides additional regularization of the ill-conditioned minimization problem.

[30] The second period is between 100 and 200-250 days when model temperature perfectly agrees with the data, while model salinity slightly $(0.1-0.2)$ deviates from observation. We speculate that during this period SIOM gradually "forgets" initial information from CTD surveys, while information from the moorings is not sufficient to control all degrees of freedom in the SIOM solution. Note that the difference between the reconstructed and observed salinity is greater on the southern mooring MA3, where the influence of the initial CTD information should be negligible due to northward flow in the Bering Strait. The reconstructed temperature is still in perfect agreement with the data, likely because strong mixing and cooling of water during winter makes the vertical temperature profile more predictable than the vertical salinity structure and reduces the effective number of degrees of freedom in the SIOM solution.

[31] During the third period (starting at day 200 and up to the end of the reconstruction), the reconstructed $T \& S$ are only in moderate agreement with the data from moorings. Note however that there is a complete lack of in situ T\&S observations in the upper layer at this time, where ice melting causes freshening of the surface waters. We conducted several numerical experiments and found that assimilation of the background climatologic data is important for obtaining realistic T\&S distribution during this period. The problem is likely related to the one-way coupling with the PIOMAS as an alternative to using the fully coupled ice-ocean model and its adjoint for variational data assimilation. So relatively large-scale fluxes at the ice-sea interface provided by PIOMAS cannot be tuned by SIOM to reproduce spring ice melting realistically without assimilation of additional data.

\subsection{Circulation Patterns}

[32] Our results show that variability of the CS circulation mainly depends on wind regime (Figure 4). This is in good agreement with all previous studies of the CS dynamics cited above.

[33] The October circulation pattern in the southern part of the CS revealed very strong eastward Siberian Coastal Current (SCC) $(0.2-0.3 \mathrm{~Sv})$ along the Siberian coast that entered the CS through Long Strait and almost reached Bering Strait. The Bering Strait inflow of Pacific water was moderate $(0.5-0.6 \mathrm{~Sv})$. Interestingly, at the same time, the major outflow from the CS was through the Herald Canyon $(0.7 \mathrm{~Sv})$, while Arctic water actually entered through the Barrow Canyon and along the eastern flank of Herald Shoal. Such influx has been observed in other years as well (see discussion by Woodgate et al. [2005c]). Inflow to the CS via these routes could be explained by strong southwestward winds of $5-8 \mathrm{~m} / \mathrm{s}$ (Figure 5).

[34] In November, monthly mean southward winds in the southern and eastern parts of the region under investigation decreased by $2-3 \mathrm{~m} / \mathrm{s}$. Since local winds usually oppose the Bering Strait inflow [e.g., Shtokman, 1957; Coachman and Aagaard, 1966], the reconstructed northward transport through Bering Strait in November increased to 0.9-1.0 Sv (compared with $0.5-0.6 \mathrm{~Sv}$ in October), and $90 \%$ of outflow was between the Herald and Hanna shoals. In addition to the
Bering Strait inflow, there was an inflow of $0.1 \mathrm{~Sv}$ through the southern part of Long Strait and inflow of $0.3 \mathrm{~Sv}$ through the western part of the Herald Canyon. The reconstructed circulation pattern was very close to the traditional schematics of the CS circulation [e.g., Coachman et al., 1975; Proshutinsky, 1986; Weingartner et al., 1999; Woodgate et al., 2005a].

[35] In December, the winds in the western part of the CS were very weak. There was a complete reversal of the SCC, and its major direction was westward. Therefore, in December, Pacific water inflowing through the Bering Strait flowed out almost equally through Long Strait, Herald Canyon, and between the Herald and Hanna shoals (Central Channel). This is a situation that has been reproduced by many numerical models testing the case when the CS circulation is driven primarily by the sea level gradient between the Pacific and Atlantic oceans (see Figure 1) [Proshutinsky, 1986; Spaulding et al., 1987].

[36] In January and February, the wind speed increased and direction was mainly southeastward. This wind regime was again accompanied by the reversal of the SCC current direction. The SCC had a mostly eastward flow in Long Strait, adding East Siberian water to the CS. The strong southward winds near the Bering Strait significantly reduced the northward Bering Strait water transport in January and then almost stopped this flow or even reversed it to flow southward in February.

[37] In March and April, the southward winds decreased and the circulation pattern became similar to that which was observed in December, i.e., a strong current $(0.6-0.8 \mathrm{~Sv})$ through Bering Strait that outflows through Long Strait, Herald Canyon, and the Central Channel.

[38] In May-July, winds over the region were from the northeast and very weak. The mean reconstructed transport through the Bering Strait during this period ranged between $0.4 \mathrm{~Sv}$ and $0.6 \mathrm{~Sv}$. The entering water outflowed through the Herald and Barrow canyons and Central Channel, while currents in Long Strait were very weak with a total net transport being westward and less than $0.1 \mathrm{~Sv}$. This circulation pattern is close to the no-wind case described by Winsor and Chapman [2004].

[39] In August 1991, the winds slightly accelerated, reaching a southward mean speed of $1.5 \mathrm{~m} \mathrm{~s}^{-1}$. It is interesting that despite an increase of southward mean wind, the Bering Strait transport slightly increased up to $0.6 \mathrm{~Sv}$. That contravenes the traditional view of the strong correlation between local winds and variability of the Bering Strait transport. Analysis of Figure 4 from Woodgate et al. [2005a] shows that at the end of July 1990 and in the middle of August 1990, wind velocity correlation significantly (approximately by $20-30 \mathrm{~cm} \mathrm{~s}^{-1}$ ) underestimates the real northward current at the MA3 mooring. This is probably an indication that, particularly when the wind is weak, other processes may influence variability of the strength of the throughflow in the Bering Strait. The analysis of the momentum balance presented below shows a significant impact of the baroclinic forcing during the summer period caused by sea ice melting and freshwater discharge. It is also possible that changes in the sea level differences between the Pacific and Atlantic oceans caused by nonlocal forcing may be responsible for this phenomenon. 


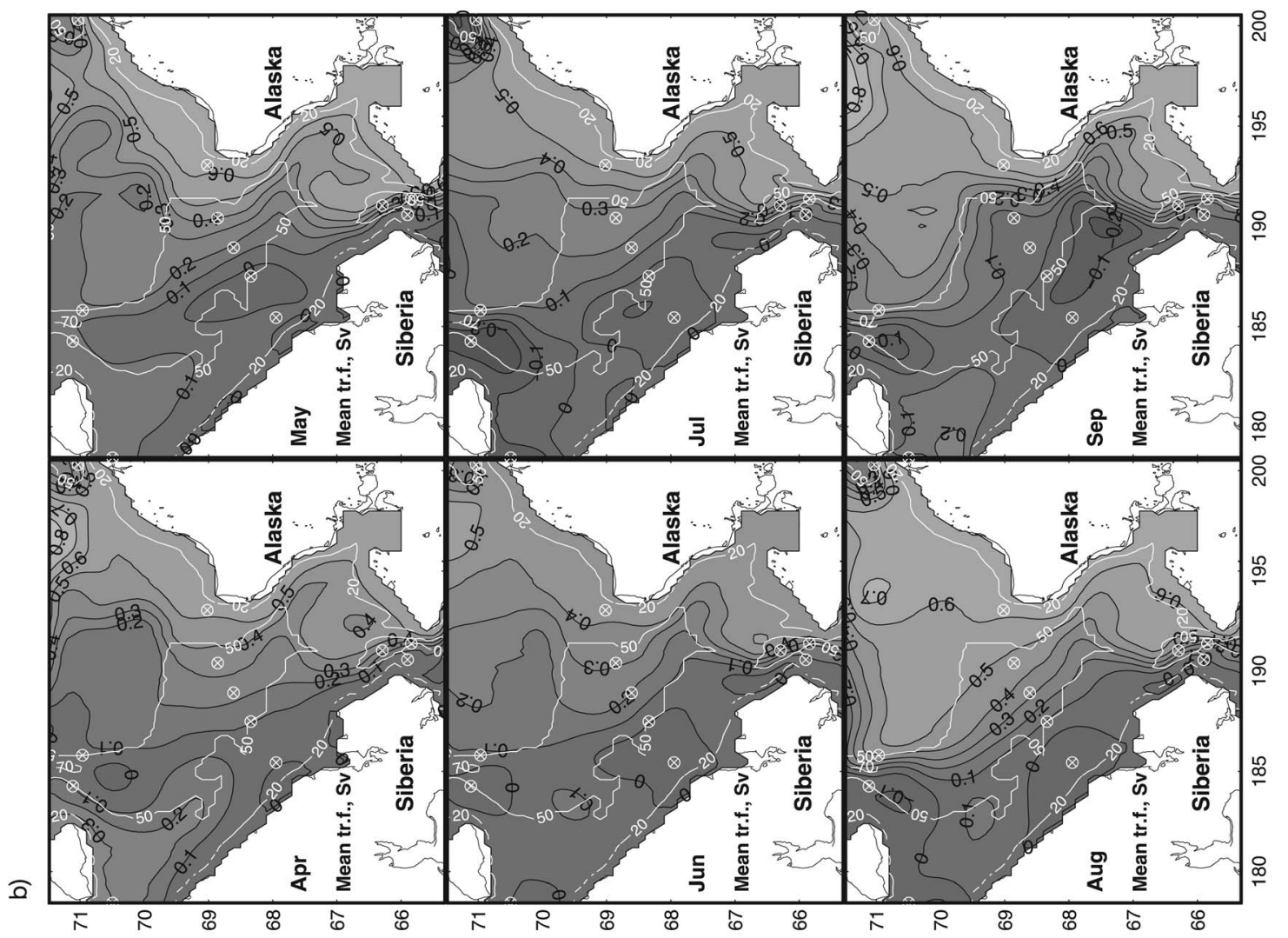

(2)

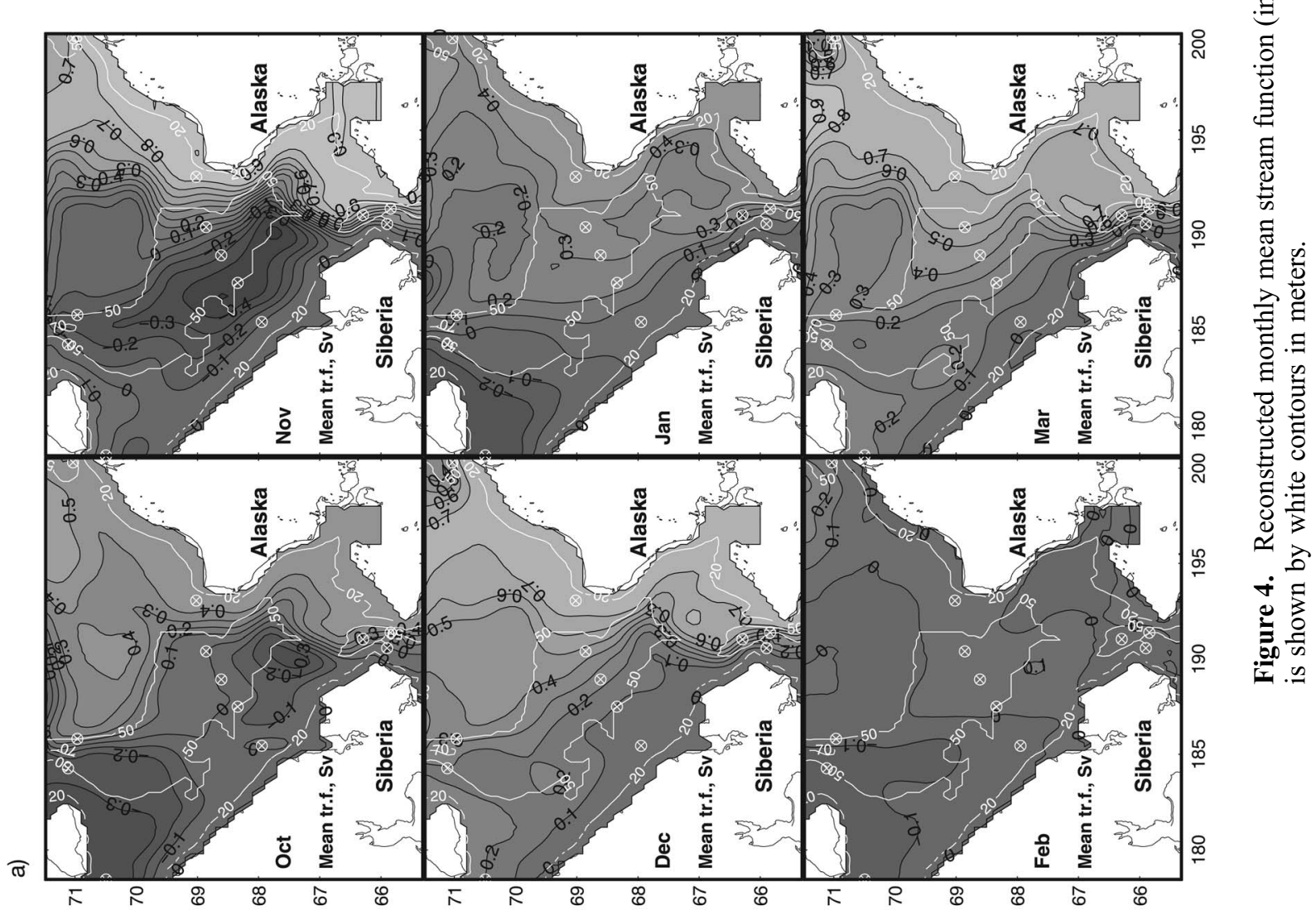



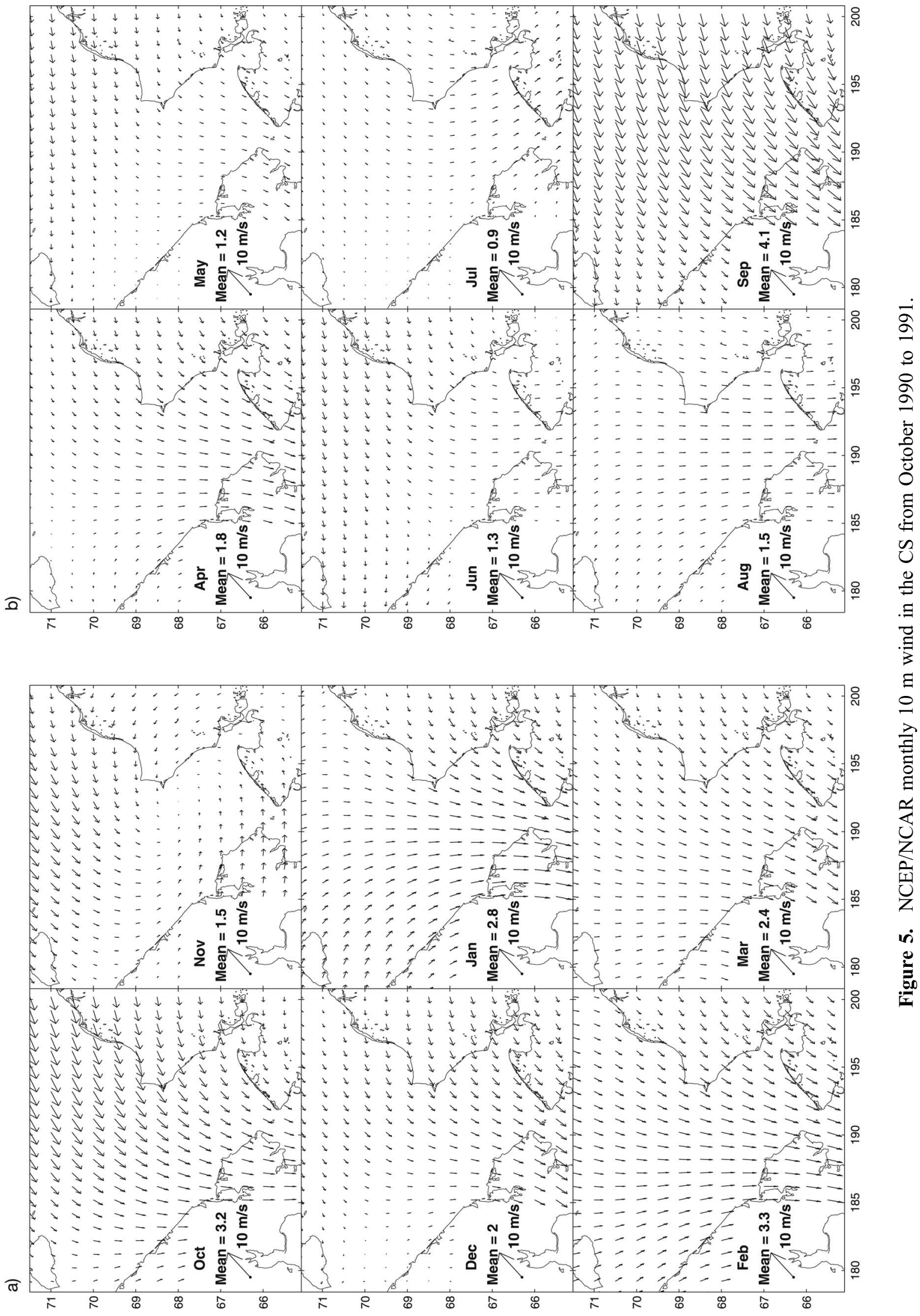


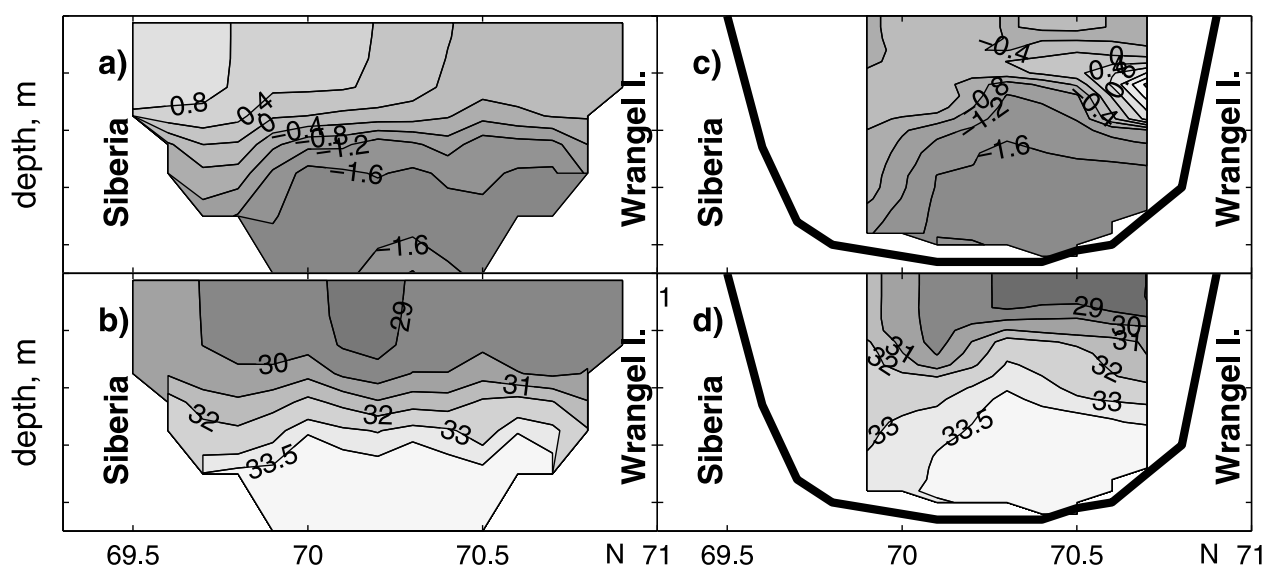

Figure 6. (a, b) Reconstructed T\&S for 25-30 September 1991 and (c, d) observed T\&S from the Long Strait section taken on 1-6 October 1991. Thick line in the left shows the bottom topography.

[40] In September 1991, winds became even stronger and turned again to the southwestward. There was a moderate similarity between winds during September 1991 and in October 1990 (Figure 5). As a result, the circulation in October 1990 and September 1991 were also similar and revealed a weak inflow through the Barrow Canyon, weak flow through the Central Channel, intensive outflow through the Herald Canyon, and a cyclonic circulation northwest from the Bering Strait $\left(67.5^{\circ} \mathrm{N}, 190^{\circ} \mathrm{E}\right)$.

[41] The only difference between September and October circulations is in Long Strait (see Figure 4, September), where the westward current along the Siberian coast is well pronounced. That is probably due to the stronger westward component of the wind in September 1991. The reconstructed net currents in Long Strait were westward (i.e., opposite of the traditional eastward SCC direction) for almost 7 months (March-September 1991). In spring, the westward transport was very strong and reached up to $0.3 \mathrm{~Sv}$. The persistent westward flow along the Siberian coast should bring saline and relatively fresh Pacific water to Long Strait and into the East Siberian Sea. These results for the winter period have many uncertainties because in winter the significant area of the East Siberian Sea is covered by the landfast ice that usually occupies the region bounded by the Siberian coast and the $25 \mathrm{~m}$ isobath. The land-fast ice blocks the wind's influence on the ocean surface and in the real world the water circulation under the fast ice is sluggish and changes under tidal forcing or due to changes in atmospheric pressure (inverted barometer effect, see experiments of Proshutinsky et al. [2007]) and due to long waves associated with wind action beyond regions occupied by land-fast ice. Pavlov et al. [1996] show that at least half of the Long Strait area (between the coast and Wrangel Island) along the coast (where the SCC is usually located) is covered by fast ice in winter while the second half of this area is covered by drifting ice and can be influenced by wind stresses via sea ice motion. This makes propagation of the Pacific water westward even easier because it is supported by the wind forcing and sea level gradient forcing discussed above. In addition, the propagation of Pacific water westward in winter can be explained by SCC reduction due to a significant seasonal decrease of Siberian river runoff which feeds the SCC, as discussed above.
[42] Water velocity and T\&S observations from mooring ME2 are the only data available in Long Strait. This mooring was deployed on the north side of the channel and thus did not sample the southward flowing SCC, which is likely topographically constrained to the south side of the channel. Our results show that ME2 velocity data do not represent well the flow in Long Strait [see also Woodgate et al., 2005a]. Instead, our simulations show several events with eastward current along the southern flank of Wrangel Island and westward flow along the Siberian coast and vice versa. This means that it is important not to use ME2 data to constrain the entire flow through Long Strait but instead to use information from other moorings to elucidate Long Strait flow via constraints of volume, heat, and salt conservation imposed on the SIOM solution.

[43] Figures $6 \mathrm{a}$ and $6 \mathrm{~b}$ show that for 25-30 September 1991 , the warm $\left(0.8^{\circ} \mathrm{C}\right)$ and saline (30.0) water occupied the Long Strait cross section near the Siberian coast and colder $\left(-0.2^{\circ} \mathrm{C}\right)$ and slightly fresher (with salinity 29.0$)$ water was located near Wrangel Island. This pattern is completely opposite to the T\&S distribution observed 1-6 October 1991 [Weingartner et al., 1999], when the eastward SCC was well developed, cold $\left(-1.25^{\circ} \mathrm{C}\right)$ and fresh (salinity, 26.5) water was near the Siberian Shelf, while saline (29.5-30.30) and warm $\left(-0.75^{\circ} \mathrm{C}\right)$ water was near Wrangel Island (see Figure 5 in Weingartner et al. [1999]).

[44] The T\&S observed 1-6 October 1991 across Long Strait (Figures 6c and 6d) were not assimilated into the model and can be used to estimate the skills of our data assimilation system. Note that there is only one mooring near Wrangel Island that (as discussed above) provides us with observations of velocity and T\&S approximately $10 \mathrm{~m}$ above the bottom (Figure 1). Despite the lack of data in the surface layers and near the Siberian coast, our reconstruction represents the temperature and salinity patterns of the CTD survey with reasonable accuracy. For example, in the bottom layer, the $-1.6^{\circ} \mathrm{C}$ isotherm and the 33.5 isohaline of the model closely resemble the observations (Figure 6). Even in the surface layer, the location of the 29 and 30 isohalines are also very similar in the observed and reconstructed fields.

[45] The observed surface temperature is colder and contains more small-scale features than the reconstructed temperature. But it is hard to expect the correct reconstruction 


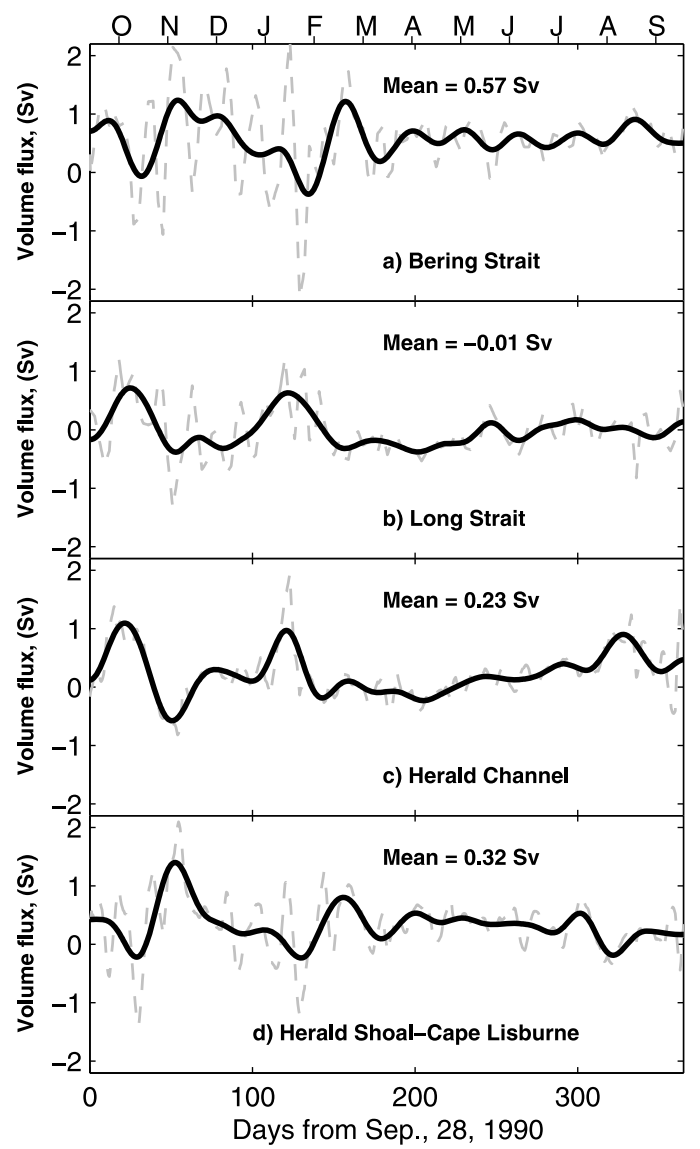

Figure 7. Time series of reconstructed volume transports in the (a) Bering Strait, (b) Long Strait, (c) Herald Channel, and (d) between Herald Shoal and Cape Lisburne. Solid lines represent 30 day cutoff low-pass filtered transports; dashed lines show unfiltered raw data.

of all these features without any real surface observations in the region. Note also that the typical two-layer structure of the hydrographic fields during the summer hinders the propagation of information from the bottom layer to the surface, and the reconstruction of the surface temperature and salinity completely depends on surface heat and salt fluxes and the skill of the vertical mixing parameterization. Both of these factors are far from ideal.

[46] The similar absence of the eastward SCC current was also observed in 1995 [Münchow et al., 1999]. According to the work of Weingartner et al. [1999], the absence of SCC in 1995 was caused by a wind anomaly in summer 1995 . Weingartner et al. [1999] stated that "in a year when our observations suggest that SCC was present, the August or September winds were either highly variable or anomalously strong and from northwest." Our Figure 5 clearly indicates that the mean winds since April 1991 were from the northwest, i.e., from the anomalous direction.

[47] Interestingly, our results indicate the existence of periodic zonal (east-west or west-east) flows along the northern flank of the Herald Shoal $\left(185^{\circ} \mathrm{E}-195^{\circ} \mathrm{E}\right.$ and $\left.71^{\circ} \mathrm{N}\right)$ and along the eastern flank of the Hanna Shoal $\left(197^{\circ} \mathrm{E}-201^{\circ} \mathrm{E}\right.$ and $71^{\circ} \mathrm{N}$ ). The zonal character of these flows is controlled by bottom topography [Spall, 2007], and their period of oscillation (west or east prevailing direction) is determined by changes of wind forcing. These currents were reconstructed even though our model domain is significantly smaller than the region modeled by Spall [2007], likely as the topographic control is very strong. We are confident that the reconstructed strong inflow along the eastern flank of the Hanna Shoal is a result of assimilation of velocity data from moorings and dynamical constraints by the model equations. The strong inflow arises when we observe strong northward current at mooring MK1 in the Barrow Canyon outflow and weak currents at mooring MC6, a proxy for the Alaskan Coastal Current input to the Barrow Canyon.

\subsection{Water Volume Balance in the Chukchi Sea}

[48] Pacific water entering the CS via the Bering Strait exits the CS along four basic pathways: Long Strait, Herald Canyon, the Central Channel, and Barrow Canyon [Woodgate et al., 2005a; Weingartner et al., 2005]. Since the model domain covers only a small part of the Barrow Canyon, we initially neglected this outflow and considered transports through the three sections across Long Strait, Herald Canyon, and the section between Herald Shoal and Cape Lisburne, respectively (Figure 1).

[49] The low-pass filtered and the mean transports through these sections and through Bering Strait are shown in Figure 7. The reconstructed mean Bering Strait transport was found to be $0.57 \mathrm{~Sv}$, which is $0.23 \mathrm{~Sv}$ (or 29\%) lower than the mean transport estimate of $0.8 \mathrm{~Sv}$ obtained by Woodgate et al. [2005a]. The disagreement between these two estimates may be related to the fact that Woodgate et al. [2005a] calculated the Bering Strait transport using velocity at a single point near the bottom of the Bering Strait Eastern Channel and a constant cross-sectional area, while our results take into account nonuniformity of the flow in Bering Strait. The Bering Strait cross-section area in SIOM is $93 \%$ of the area utilized in the Woodgate et al. [2005a] calculations (4.04 and $4.35 \mathrm{~km}^{2}$, respectively). The transport calculation method of Woodgate et al. [2005a] applied to the reconstructed velocity produces the mean Bering Strait transport of $0.82 \mathrm{~Sv}$, which practically coincides with the Woodgate et al. [2005a] estimate. Clement et al. [2005] analyzed the mean climatologic state calculated as a 23 year mean of the Pan-Arctic model and tested the robustness of the Bering Strait transport estimates obtained from a single velocity observation location. They suggested that the method utilized in several publications [e.g., Roach et al., 1995; Woodgate et al., 2005b] overestimates the mean Bering Strait transport by approximately $0.22 \mathrm{~Sv}$, i.e., exactly by the same amount as the difference between our results and Woodgate et al. [2005a], but it should be remembered that this model has only 10 grid points across the strait. However, we do not suggest that our estimate of the Bering Strait transport is closer to reality than the results of Woodgate et al. [2005a].

[50] Field observations indicate that the traditional estimates of the Bering Strait transport may actually underestimate the transport as they neglect approximately $0.1 \mathrm{~Sv}$ transport of the seasonal Alaskan Coastal Current (ACC) in the upper water column [e.g., Woodgate and Aagaard, 2005]. Both results from the Clement et al. [2005] model and from our reconstruction employing the 4D-var assimilating approach have limited spatial resolution in the strait and may fail reproducing this current reliably. A high-resolution 


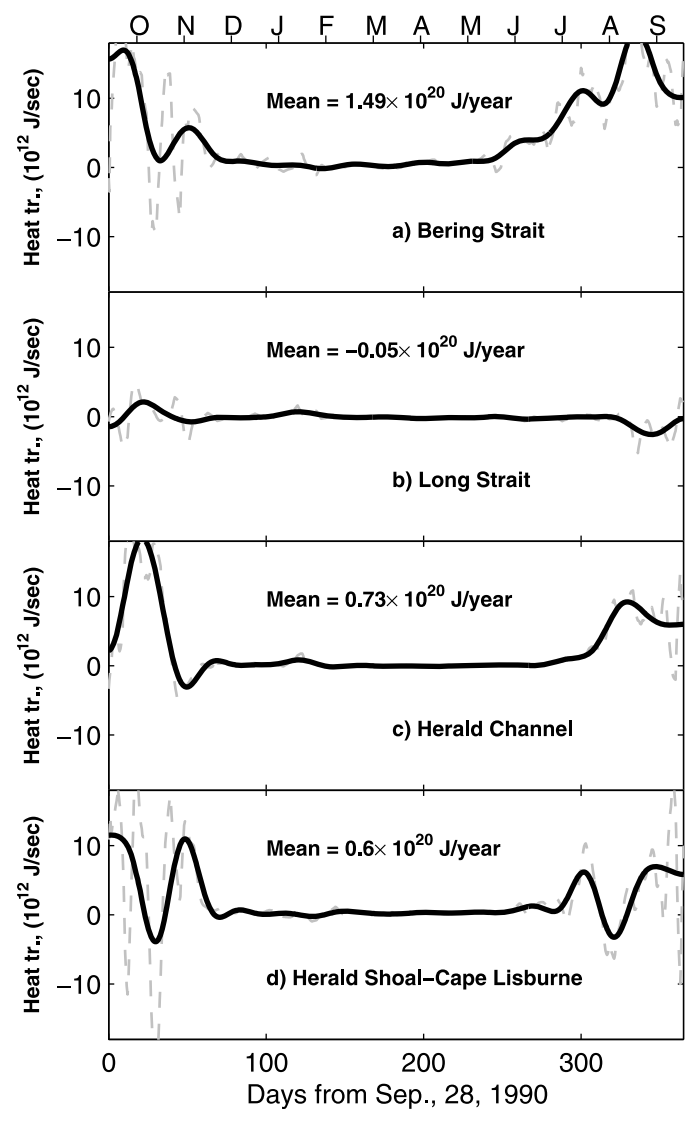

Figure 8. Time series of reconstructed heat transports computed relative to $-1.9^{\circ} \mathrm{C}$ through the (a) Bering Strait, (b) Long Strait, (c) Herald Channel, and (d) between Herald Shoal and Cape Lisburne. Solid lines represent 30 day cutoff low-pass filtered transports; dashed lines depict unfiltered transports.

mooring array currently deployed in the Bering Strait should resolve the issue.

[51] Our results indicate that the mean transport through the eastern (U.S.) channel of the Bering Strait was larger by $0.21 \mathrm{~Sv}$ than the mean transport through the eastern channel $(0.18 \mathrm{~Sv})$. The relative importance of the eastern channel flow in the Bering Strait transport calculations was also found by Woodgate et al. [2005a], who obtained estimates of 0.3 and $0.5 \mathrm{~Sv}$ for $1990-1991$ mean transports from the western and eastern channels, respectively. This difference is also seen by Panteleev et al. [2009], who conducted a sensitivity study of circulation in the northern Bering Sea.

[52] Our results suggest that approximately half of the Pacific water $(0.33 \mathrm{~Sv})$ outflow occurs between Herald Shoal and Cape Lisburne. Analysis of the maps shown in Figure 4 indicates that after passing Cape Lisburne this flow splits into two branches and exits the CS through the Central Channel and between Hanna Shoal and Icy Cape (Figure 1, dashed lines). The mean transport through the Central Channel $(0.19 \mathrm{~Sv})$ is not significantly larger than the transport between Hanna Shoal and Icy Cape $(0.14 \mathrm{~Sv})$. The flow between Herald Shoal and Cape Lisburne shows significant correlations with the Bering Strait transport (correlation 0.73), while its branches reveal only moderate correlation of 0.64 and 0.54 with the Bering Strait transport.
High correlation between the Bering Strait flow and outflow through the Central Channel agrees well with the spatial structure of the first EOF mode of the principal component of velocity at each mooring presented by Woodgate et al. [2005a].

[53] The mean transport through Herald Canyon is $0.23 \mathrm{~Sv}$, which is only $70 \%$ of the transport between Hanna Shoal and Icy Cape. This estimate is close to $0.28 \pm 0.06 \mathrm{~Sv}$ obtained by Woodgate et al. [2005a]. The dominance of the flow between Herald Shoal and Cape Lisburne over other pathways of Pacific water into the Arctic Ocean agrees with the modeling results of Spall [2007], based on a high-resolution baroclinic model and contradicts the results of the barotropic model employed by Winsor and Chapman [2004]. As in the work of Woodgate et al. [2005c], we found that the flow in Herald Canyon does not correlate with the Bering Strait transport (correlation is 0.08 ) but is moderately correlated (negatively) with the flow through Long Strait $(-0.56)$. This result is in agreement with the low correlation between velocity in Herald Canyon and local wind reported by Woodgate et al. [2005a]. Low correlation with the Bering Strait transport indicates that the currents in Herald Canyon could be influenced by the processes occurring (forced) outside of the model domain (e.g., by periodic formation of the anticyclonic circulation around Wrangel Island clearly seen in the transport stream function for NovemberDecember, March-June, and September in Figure 4).

[54] The mean flow through Long Strait was in both directions with transports $-0.06 \mathrm{~Sv}$ (westward) and $0.05 \mathrm{~Sv}$ (eastward) in the southern and northern parts of Long Strait, respectively. The annual mean flow through Long Strait is almost zero, as estimated by Woodgate et al. [2005a], while Figure $7 \mathrm{~b}$ indicates significant variability of the total transport through Long Strait. According to Figure 7b, the periods with dominant eastward or westward flow can easily last as long as $60-100$ days with transports of $0.5-1.0 \mathrm{~Sv}$ in both directions. Obviously, these reversing transports may result in significant water exchange between the East Siberian and CS seas and thereby strongly influence the local ecosystems. For example, as we mentioned above, since March 1991, the total flow through Long Strait was mostly westward causing accumulation of the anomalously warm $\left(0.4^{\circ} \mathrm{C}\right)$ and saline water near the Siberian coast (Figure 6). Our results reveal moderate (0.56) correlation between Long Strait and Bering Strait transports likely because both SCC and the Bering Strait transport are influenced by local winds. Figures $7 \mathrm{a}$ and $7 \mathrm{~b}$ show at least six events during October 1990 to February 1991 when the reverse (up to $2 \mathrm{~Sv}$ southward) of the Bering Strait current coincides with the strong (up to $1.5 \mathrm{~Sv}$ ) inflow through Long Strait.

[55] The spatial structures of the principal component (EOF) of the velocities at each mooring [Woodgate et al., 2005a, Figure 3] do not show such correlation likely because they lack data from the Long Strait inflow; their EOFs are based on the ME2 mooring, which likely measures the outflow through Long Strait flow as discussed above. This shows one of the strengths of the 4D-var; one mooring near Wrangel Island does not allow one to reconstruct the total transport through Long Strait, but the 4D-var data assimilation effectively projects the information from other moorings to Long Strait by the dynamical constraints of the SIOM. 


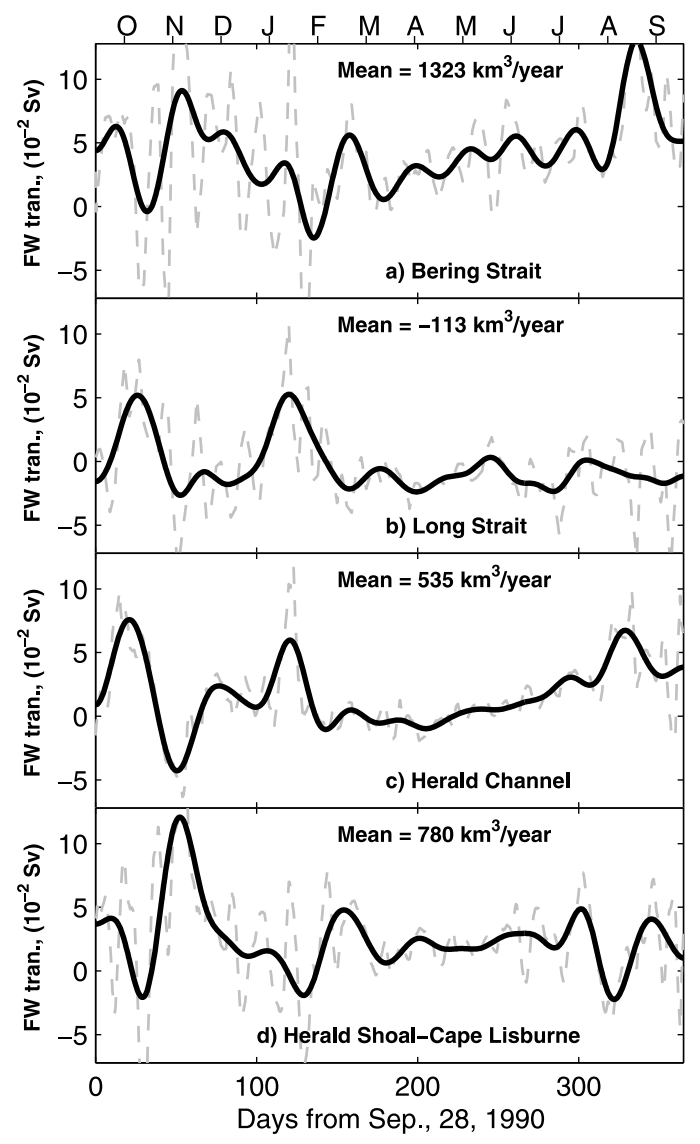

Figure 9. Time series of reconstructed freshwater transports computed relative to a reference salinity of 34.8 . Transports through the (a) Bering Strait, (b) Long Strait, (c) Herald Channel, and (d) between Herald Shoal and Cape Lisburne are shown. Solid lines represent 30 day cutoff lowpass filtered transports, and dashed lines depict unfiltered transports.

[56] Transports shown in Figure 7 have strong variability in fall, winter, and early spring. In late spring (days 180-200), the fluctuations of the currents decreased and a "calm" period continued until August 1991 (days 270-300 in Figure 7). Such behavior of the transports is in agreement with respectively strong and weak winds during corresponding months (see Figure 5).

\subsection{Heat and Salt Balance in the Chukchi Sea}

[57] The heat and freshwater transports (Figures 8 and 9) through the sections (1-4) (Figure 1) were calculated relative to freezing temperature, $T_{\mathrm{f}}=-1.9^{\circ} \mathrm{C}$ [see Woodgate et al., 2005a] and mean arctic salinity of 34.8 [Aagaard and Carmack, 1989]. The heat transports through the Bering Strait, Herald Canyon, and between the Herald Shoal-Cape Lisburne exhibit a significant seasonal cycle with positive northward heat transport in fall and summer.

[58] In winter, the heat transports through all sections are negligibly small because the water temperature is close to the freezing point. The clear seasonal temperature cycle and conventionally northward throughflow via the CS result in 0.4-0.7 correlation coefficients (Table 3) between the heat transport through the Bering Strait and other sections shown
Table 1. Optimized Annual Mean Volume Transport ${ }^{\mathrm{a}}$

\begin{tabular}{ccccccccccc}
\hline Section & BS & BSE & BSW & LS & LSS & LSN & HC & CL & HS & IC \\
\hline $\begin{array}{c}\text { Transport, } \\
\text { Sv }\end{array}$ & 0.57 & 0.39 & 0.18 & -0.01 & 0.05 & -0.06 & 0.23 & 0.33 & 0.19 & 0.14 \\
\hline
\end{tabular}

${ }^{\mathrm{a}}$ Unit is in Sv. Through Bering Strait (BS) and its eastern (BSE) and western (BSW) channels, Long Strait (LS), southern part of Long Strait (LSS), northern part of Long Strait (LSN), Herald Canyon (HC), between Herald Shoal and Cape Lisburne (HS-CL), between Herald and Hanna shoals (HS-HS), and between Hanna Shoal and Icy Cape (HS-IC).

in Figure 1. Surprisingly, we find no clear seasonal cycle in the freshwater transport shown in Figure 9, possibly due to smaller variability of salinity in the CS. The minimum and maximum of the freshwater transport are in February and August, respectively, i.e., in the months with the strongest rates of freezing and melting of the ice. Interestingly, it appears that the $4 \mathrm{D}$-var data assimilation system does reasonably reconstruct the variability of the freshwater transport even in the absence of the salinity data in the surface layers of water. The correlation matrix for freshwater transports (Table 3 ) is rather similar to the volume transport correlation matrix, likely since, as discussed by Woodgate et al. [2006], the freshwater transport variability is more strongly driven by volume transport variability than by salinity variability.

[59] However, the heat transport correlation matrix (Table 3) is somewhat different. For example, the Herald Canyon heat transport correlates positively with the heat transport between Herald Shoal and Cape Lisburne, while correlation between corresponding volume transports is negative. We speculate that this correlation pattern is due to seasonal variability of water temperature in the central and eastern parts of the CS, which usually increases correlation.

[60] The maximum heat transport through Bering Strait (Figure 8a) was at the beginning of October 1990 due to strong northward currents and relatively warm waters during this period. The mean heat transport during 1990-1991 was $1.49 \times 10^{20} \mathrm{~J} \mathrm{yr}^{-1}$ (Table 4). Taking into account that our volume transport is only $72 \%$ of the transport estimated by Woodgate et al. [2005a], we obtain that the "adjusted" heat transport through Bering Strait in 1991 is $2.07 \times 10^{20} \mathrm{~J} \mathrm{yr}^{-1}$; i.e., it is almost the same as the heat transport of $2.10 \times$ $10^{20} \mathrm{~J} \mathrm{yr}^{-1}$ for 1991 estimated by Woodgate et al. [2006].

Table 2. Correlation Matrix of Simulated Currents ${ }^{\mathrm{a}}$

\begin{tabular}{lllllll}
\hline Sections & \multicolumn{1}{c}{ BS } & LS & HC & HS-CL & $\begin{array}{c}\text { HS- } \\
\text { HS }\end{array}$ & $\begin{array}{c}\text { HC } \\
\text { IC }\end{array}$ \\
\hline BS & 1 & $-0.56 /-0.60$ & $0.08 /-0.20$ & $0.73 / 0.71$ & 0.64 & 0.54 \\
LS & $-0.56 /-.60$ & 1 & $0.50 / 0.75$ & $-0.31 /$ \\
HC & $0.08 /-0.20$ & $0.50 / 0.75$ & 1 & -0.60 \\
HS-CL & $0.73 / 0.71$ & $-0.31 /-0.60$ & $-0.37 /$ & 1 & $-0.37 /$ \\
HS-HS & 0.64 & & -0.70 & -0.70 & 0.86 & 0.78 \\
HS-IC & 0.54 & & & 0.86 & 1 & 0.35 \\
\end{tabular}

${ }^{\mathrm{a}}$ Via Bering Strait (BS), Long Strait (LS), Herald Canyon (HC), between Herald Shoals and Cape Lisburne (HS-CL), between Herald and Hanna Shoals (HS-HS), and between Hanna Shoal-Icy Cape (HS-IC). Set of two numbers shown in some nondiagonal cells presents the correlations for unfiltered and 30 day cutoff low-pass filtered currents, respectively. 
Table 3. Correlation Matrix for Reconstructed Low-Pass Filtered Heat and Salt Transport ${ }^{\mathrm{a}}$

\begin{tabular}{lllll}
\hline Section & BS & \multicolumn{1}{c}{ LS } & HC & HS-CL \\
\hline BS & 1 & $-\mathbf{0 . 4 0}$ & $\mathbf{0 . 6 3}$ & $\mathbf{0 . 7 0}$ \\
LS & -0.41 & 1 & $\mathbf{0 . 2 0}$ & $\mathbf{0 . 4 4}$ \\
HC & 0.21 & 0.54 & 1 & $\mathbf{0 . 1 2}$ \\
HS-CL & 0.49 & -0.47 & -0.57 & 1 \\
\hline
\end{tabular}

${ }^{a}$ Low-pass filtered heat (bold, upper triangle) and salt (italic, bottom triangle) transport through Bering Strait (BS), Long Strait (LS), Herald Canyon (HC), and between Herald Shoal and Cape Lisburne (HS-CL) at zero time lag.

[61] The mean heat transport through Herald Canyon and between Herald Shoal and Cape Lisburne was $0.73 \times$ $10^{20} \mathrm{~J} \mathrm{yr}^{-1}$ and $0.60 \times 10^{20} \mathrm{~J} \mathrm{yr}^{-1}$ (Table 4). Thus, in contrast to what we observed with the volume transport, Herald Canyon is the major conduit for the heat export into the Arctic Ocean; the mean annual transport through Herald Canyon was approximately $20 \%$ higher than the heat transport between Herald Shoal and Cape Lisburne. We note, however, that Woodgate et al. [2006] speculate that the Alaskan Coastal Current may be an important part of the heat flux into the Chukchi. Interestingly, the freshwater export through the Central Channel is still smaller than the freshwater transport via Herald Canyon.

[62] We speculate that the smaller heat transport through the Central Channel occurred due to strong winter cooling near the Alaska coast. The winter cooling near the Alaska coast can be also related to significant brine rejection in polynyas and a water salinity increase [e.g., Weingartner et al., 1998]. That may amplify/decrease the salt/freshwater transport between Hanna Shoal and Icy Cape during the winter and early spring periods.

[63] The heat transport through Long Strait (Figure 8a) is almost constant year around and close to zero because of relatively cold local temperatures in the western Chukchi and East Siberian seas all year around. Note that the negative heat transport and positive salt transport through Long Strait in July-September 1991 corresponds to the eastward flow of the SCC discussed above (Table 1).

[64] Due to the similarity between the volume and freshwater transport correlation matrices (Tables 2, 3, and 4), the temporal evolution of the freshwater/salt transports (Figure 9) in general correlates positively/negatively with the volume transport (Figure 7). There are some exceptions. For example, the maximum freshwater transport through Bering Strait was in August-September 1991, when the small increase of the volume transport (Figure 7a) occurred simultaneously with 0.40 drop of salinity at mooring MA3 (Figure 1). The analysis of salinity and velocity at mooring MA1 (as well as analysis of the momentum balance presented below) reveals that this

Table 4. Optimized Mean Heat and Freshwater Transports ${ }^{\mathrm{a}}$

\begin{tabular}{llllc}
\hline Section & BS & LS & HC & HS-CL \\
\hline Heat & 1.49 & -0.05 & 0.73 & 0.60 \\
Fresh water & 1266 & -113 & 532 & 778 \\
\hline
\end{tabular}

${ }^{\mathrm{a}}$ Mean heat (in $10^{20} \mathrm{~J} \mathrm{yr}^{-1}$, relative to $-1.9^{\circ} \mathrm{C}$ ) and freshwater $\left(\mathrm{km}^{3} \mathrm{yr}^{-1}\right.$ relatively to reference salinity of 34.8) transports through Bering Strait (BS), Long Strait (LS), Herald Canyon (HC), and between Herald Shoal and Cape Lisburne (HS-CL).

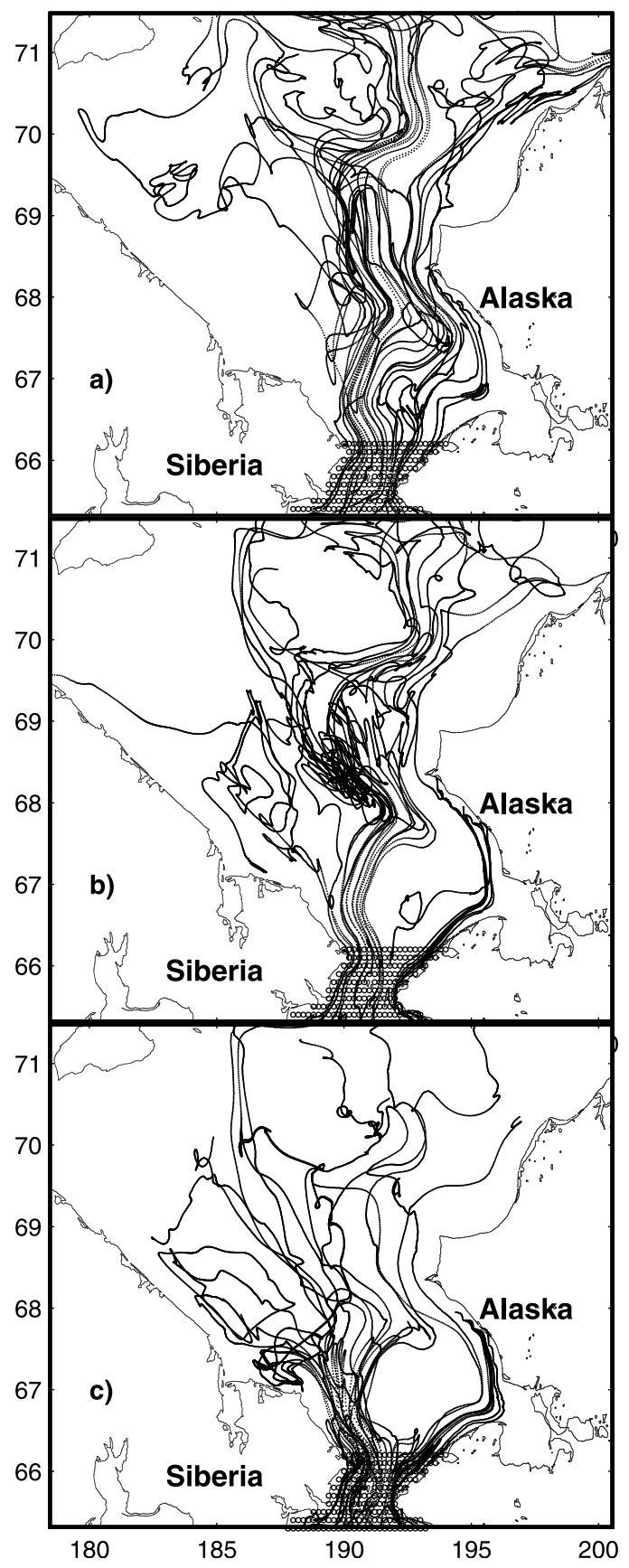

Figure 10. Trajectories of the particles launched in the vicinity of Bering Strait at the beginning of (a) October 1990, (b) January 1991, and (c) April 1991.

was due to an increase of low-saline water flow through the eastern part of the Bering Strait.

\subsection{Residence Time of the Pacific Water in the Chukchi Sea}

[65] To estimate the residence time of Pacific water in the $\mathrm{CS}$, we launched Lagrangian particles in the vicinity of Bering Strait (Figure 10a) and calculated their trajectories with a standard Runge-Kutta fourth order accuracy algorithm [Roache, 1998]. The particles were launched at regular intervals every 30 days between 28 September 1990 


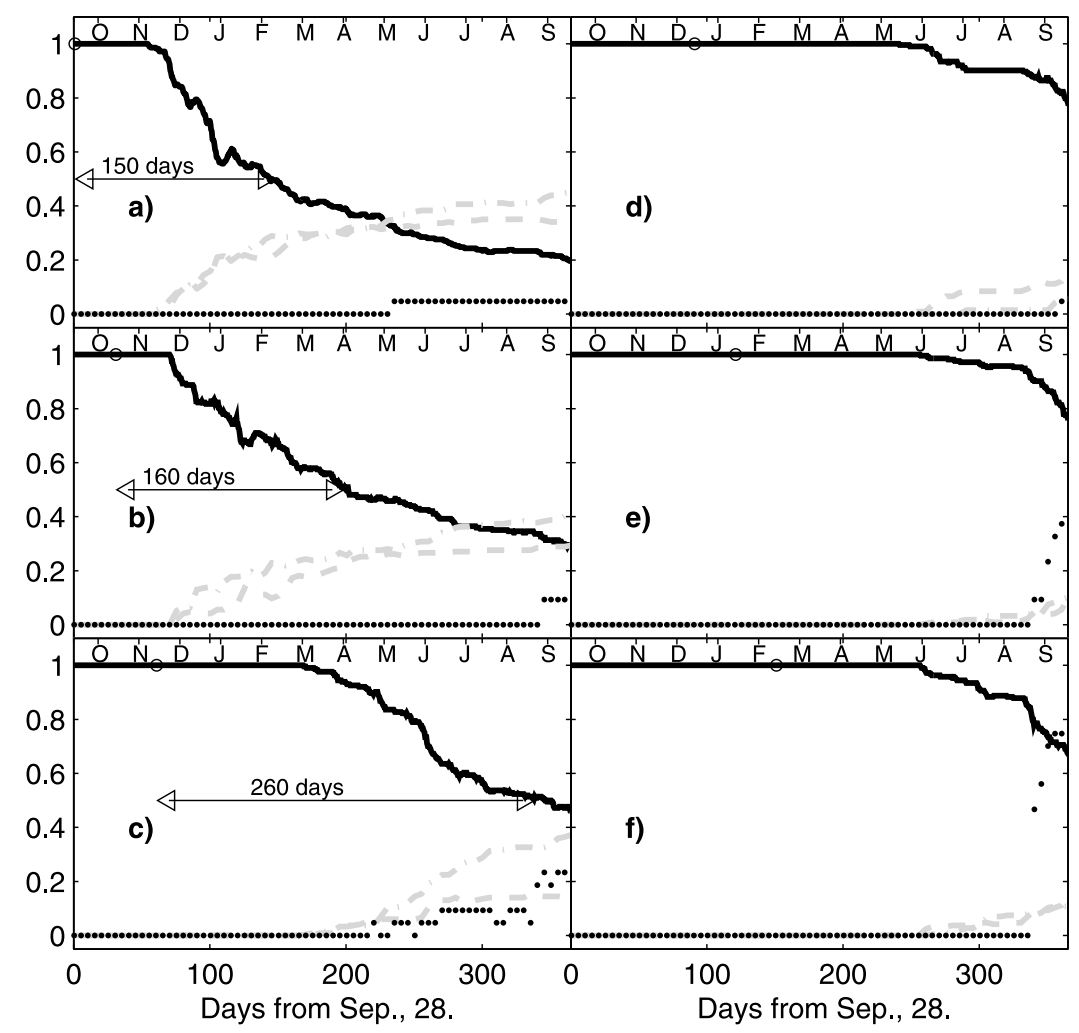

Figure 11. Fraction of number of particles (solid black line) launched in the Bering Strait and residing in the regions 1 (black dotted), 2 (gray dashed), and 3 (gray dash-dotted). The corresponding regions are shown in Figure 1. The particles were launched at the beginning of (a) October, (b) November, (c) December, (d) January, (e) February, and (f) March, as indicated by circles on the solid black lines. Since only a small portion of particles exit through Long Strait, for convenience of presentation, the fraction of particles residing in the region 1 is multiplied by 10 . Arrows show the typical residence time of the particles in the CS.

and 28 February 1991. Simulation results show that there is a strong tendency for seasonal changes in the basic particle routes (Figure 10). For example, most of the particles started on 28 September 1990, exit the CS between Herald Shoal and Cape Lisburne, while particles started in April exit the CS through the Herald Canyon.

[66] Following the particles in each region (Figure 11) allows us to estimate their residence time in the CS region and the relative importance of the flows through Long Strait, Herald Canyon, and between Herald Shoal and Cape Lisburne. For example, the fastest particles launched in the vicinity of Bering Strait on 28 September (Figure 11a) leave the CS about 2 months later almost simultaneously through northern and eastern boundaries of our model (Central Channel and Barrow Canyon). But it takes about 8 months for particles from Bering Strait to exit through Long Strait. The residence time of Pacific water (Figure 11) (estimated as the time when $50 \%$ of the particles have left the CS) varies strongly during the year as suggested by Woodgate et al. [2005a]. The residence time was 150-160 days for the particles started in October-November 1990, but it increased up to 260 days for particles started in December. Taking into account the weaker currents in late winter and spring (Figure 4 ), we may expect even longer (1-1.5 years) residence time for the particles that entered into the CS via Bering Strait. The fraction of particles that move between
Herald Shoal and Cape Lisburne (dash-dotted gray line in Figure 11) is usually larger than the fraction transiting the Herald Canyon (dashed gray line at Figure 11). Interestingly, despite the persistent westward flow along the Siberian coast, the number of particles reaching the ESS (region 1 at Figure 1) is usually small, and it takes at least 6-7 months for the fastest particles to travel from Bering Strait to Long Strait.

[67] Long Strait is a potential gate for the flow from ESS into the CS.

[68] Therefore, we conducted a similar particle study starting in Long Strait (see Figures 12 and 13). Because of the net westward flow through Long Strait, the majority of these particles retroflect in the CS and return through Long Strait into the ESS. Additionally, our study shows that water from Long Strait can easily feed the northward flow through Herald Canyon and under favorable conditions may even exit the CS through the Central Channel or sometimes reach Bering Strait (Figure 12a). Similarly to the Bering Strait particles, there is a strong tendency for the Long Strait particles to flow mostly westward during spring and summer (Figure 13).

[69] Thus, particles entering the CS via Long Strait may exhibit a variety of different behaviors. A particle launched in Long Strait in April-July typically stays in the CS from 1 to 30 days and usually leaves the CS through Long Strait 


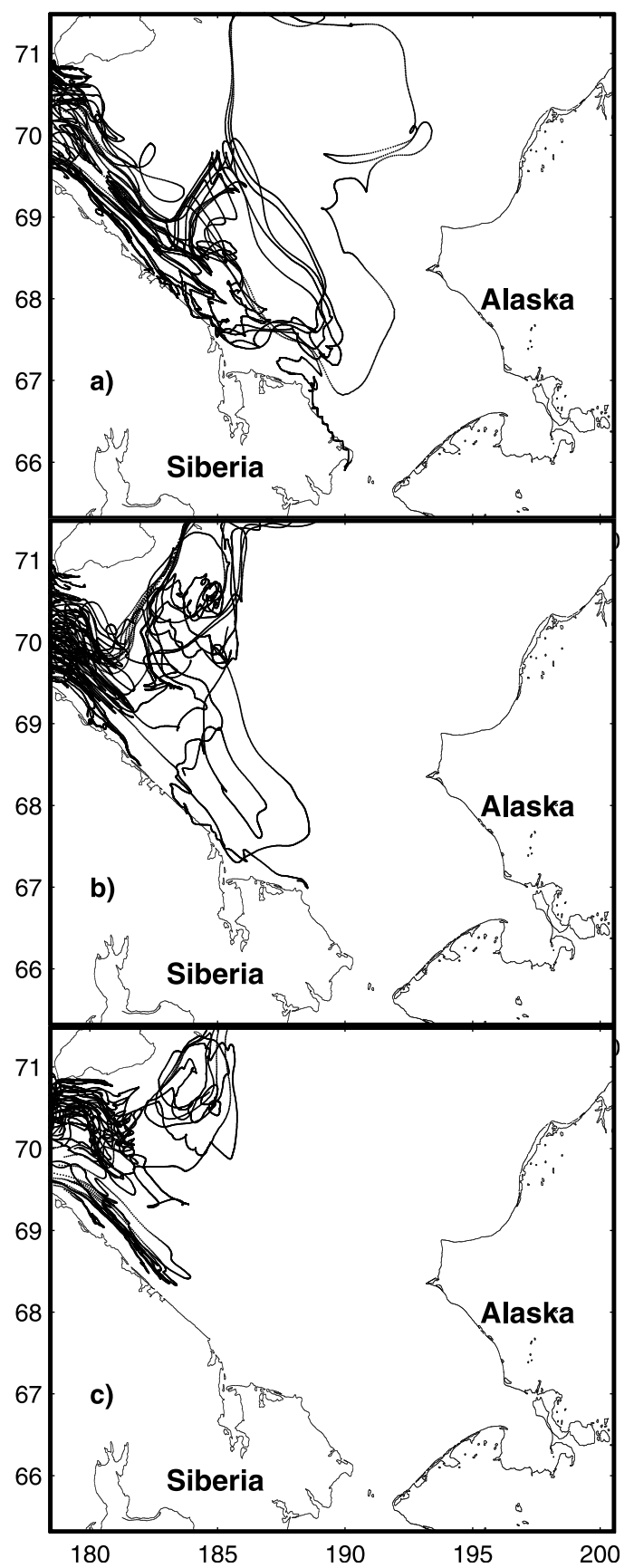

Figure 12. Trajectories of particles launched in the vicinity of Long Strait at the beginning of (a) October 1990, (b) January 1991, and (c) April 1991.

with the persistent westward flow. The other particles originating in Long Strait may reside in the CS for up to 3-4 months. In this case, the particles usually exit through Herald Canyon, but some particles reach Bering Strait.

\subsection{Momentum Balance}

[70] To provide an insight into the causes and mechanisms of the CS water dynamics, we calculated spatial averages of the various terms in the vertically averaged momentum equations for the entire period of the reconstructed circulation
(Figure 14). The west-east and south-north flow accelerations have the signs corresponding to the left hand side of the equation. The pressure gradient force components due to the sea surface slope and density anomaly (hereafter referred to as barotropic and baroclinic pressure gradients, respectively), Coriolis acceleration terms, surface and bottom stresses, and advective terms have the signs corresponding to the right-hand side of the equation. As one might expect, the geostrophic balance between the barotropic pressure gradient and the Coriolis force dominates for most of the integration period. The annual mean amplitude of the barotropic pressure gradient reaches values of approximately $80 \times 10^{-6} \mathrm{~m} \mathrm{~s}^{-2}$, while the typical amplitude of the water acceleration term is less than $4 \times 10^{-6} \mathrm{~m} \mathrm{~s}^{-2}$. In the annual mean, the impact of the surface stresses is relatively small, and in average over the whole time period the wind forcing does not exceed $5 \%-10 \%$ of the barotropic pressure forcing. In a related study, Woodgate et al. [2005a] show that while the mean velocity in the Bering Strait system including winds is $\sim 30 \mathrm{~cm} / \mathrm{s}$, under zero wind conditions the velocity is $40 \mathrm{~cm} / \mathrm{s}$. This confirms conclusions of previous studies [e.g., Shtokman, 1957; Coachman and Aagaard, 1966] that local wind is not the dominant forcing of the quasi-permanent component of the velocity in the Bering Strait. There are however several occasions in September-November (Julian days 270-330) when in the absence of ice cover the surface stress term reached 20-50 $\times$ $10^{-6} \mathrm{~m} \mathrm{~s}^{-2}$; i.e., the wind stresses were comparable with the Coriolis and sea surface pressure gradient terms. A similar balance was obtained by Spaulding et al. [1987], who employed a barotropic model for the study of the circulation in Bering Strait. In our model, the baroclinic pressure terms have a time mean amplitude on the order of $2-3 \times 10^{-6} \mathrm{~m} \mathrm{~s}^{-2}$. The baroclinic impact is small in winter and spring but increases up to $5 \times 10^{-6} \mathrm{~m} \mathrm{~s}^{-2}$ during the late summer, beginning in the fall (Julian days 170-330) due to seasonal changes in the local T\&S fields. Both bottom stress and advection terms are very small and do not play a significant role in the time-mean momentum balance.

[71] Spatial distribution of the geostrophic terms (Coriolis term and sea surface pressure gradient) exhibits (Figure 15) several distinct maxima. The clearly seen chain of maxima with amplitudes larger than $20 \times 10^{-6} \mathrm{~m} \mathrm{~s}^{-2}$ starts west of the Diomede Islands then follows the path along the Central Channel and continues toward the Barrow Canyon. This chain coincides with an intense flow of Pacific water into the Canada basin, indicating that the geostrophy plays an important role in the Pacific water transport. Another maximum with amplitude more than $20 \times 10^{-6} \mathrm{~m} \mathrm{~s}^{-2}$ is located near Wrangel Island. The location of this maximum agrees well with the periodic water inflow into the CS along the eastern coast of Wrangel Island described above. We found that geostrophic terms are higher during the summer and fall probably due to the higher Bering Strait water transport (Figure 14), but their spatial distribution is very similar for all seasons. The impact of the surface stress is very uniform and small (Figure 15c), the former obviously due to large spatial scale of the wind forcing. Although, as we mentioned above, the impact of the baroclinic pressure gradient on the CS circulation is small, there are several regions where baroclinic currents can be significant (Figure 15). The first region is the east channel of the Bering Sea where the 


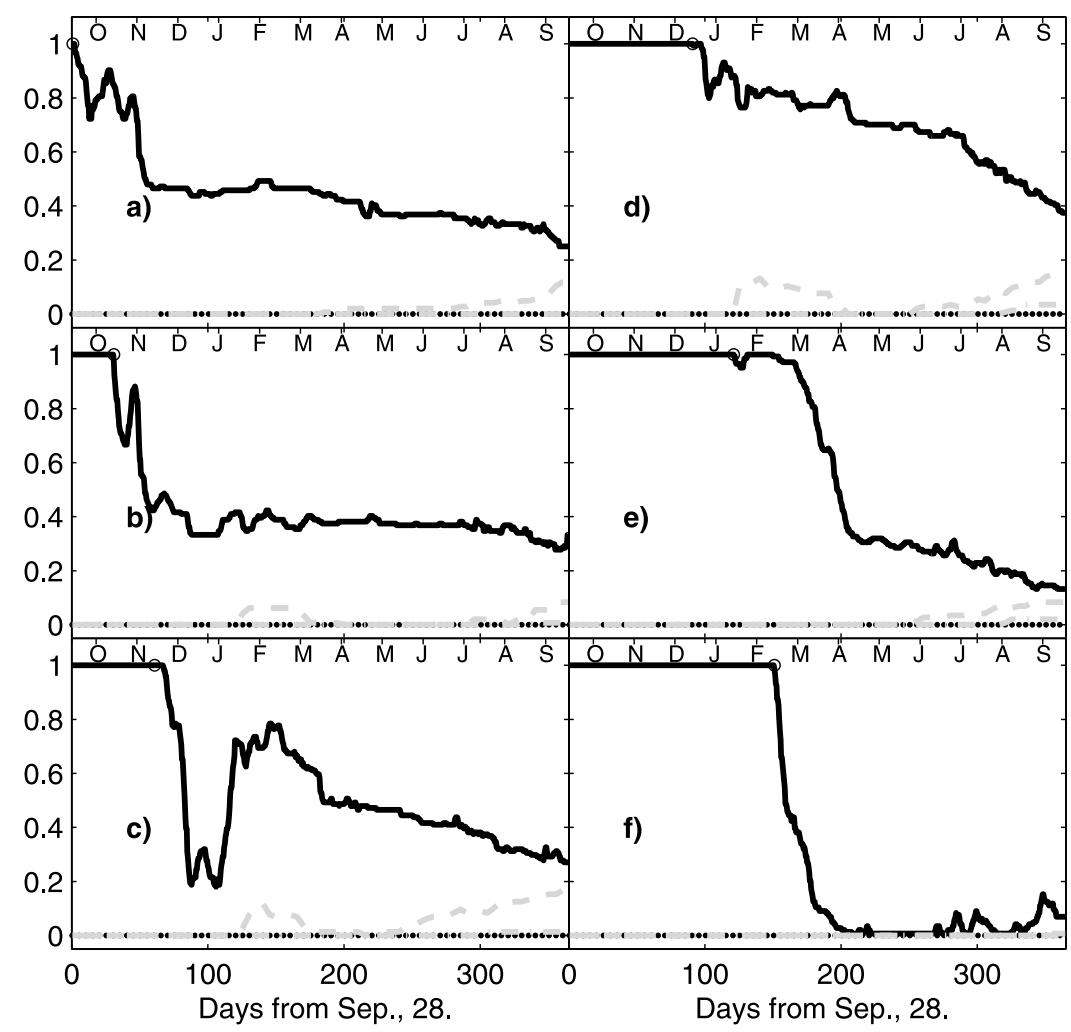

Figure 13. Same as Figure 11 but for the particles launched in Long Strait.

amplitude of the baroclinic term is about $10 \times 10^{-6} \mathrm{~m} \mathrm{~s}^{-2}$, i.e., almost $25 \%$ of the amplitude of geostrophic terms in this region (Figures $15 \mathrm{a}$ and $15 \mathrm{~b}$ ). This likely relates to the seasonal changes of the Alaskan Coastal Current [Woodgate et al., 2005b]. The second region is located on the northern flank of the Barrow Canyon where the annually averaged amplitude of the baroclinic term is $30 \%-40 \%$ of the amplitude of the barotropic pressure gradient. In order to better identify the regions where baroclinicity plays a significant role, we calculated a ratio between the mean amplitudes of the baroclinic pressure gradient and Coriolis terms and averaged them annually, for summer-fall, and for the winter period. The baroclinicity (Figures 16a and 16b) is usually important in the Bering and Long straits and in the Barrow and Herald canyons, i.e., in the regions where different water masses form local frontal zones. This forcing is usually rather strong during the summer and fall, while in winter the baroclinic impact in the straits and canyons is usually $2-4$ times weaker due to strong cooling and mixing and general homogenization of the water column. This results also in the significant reduction of the horizontal density anomaly gradients (Figures 16b and 16c).

[72] There are also several maxima of the baroclinic and Coriolis terms ratio along the Siberian coast near Cape Lisburne and in the western part of the CS. These maxima (Figures 16b and 16c) are 2-3 times stronger in winter than in other seasons. According to the works of Cavalieri and Martin [1994], Weingartner et al. [1998], and Martin et al. [2004], there is a strong generation of cold and saline water in the local permanent or quasi-permanent polynyas in these regions in winter.

\section{Summary and Concluding Remarks}

[73] The CS circulation was reconstructed from in situ ocean and remotely sensed sea ice data for late September 1990-October 1991. The observations are processed by a two-step data assimilation algorithm where at the first step the sea ice data are assimilated into a coupled ice-ocean model, PIOMAS, using nudging-type data assimilation and forced by NCEP/NCAR atmospheric fluxes. At the second step, the ocean observations and PIOMAS ice-ocean surface fluxes are assimilated into an ocean only model, SIOM, using a conventional 4D-var data assimilation technique.

[74] The 1990 and 1991 years were characterized by a cyclonic Arctic Ocean circulation regime [Proshutinsky and Johnson, 1997] driven by winds of the reduced Arctic High and expanded influence of the Icelandic minimum on the arctic atmospheric circulation (high Arctic Oscillation index) [see Thompson and Wallace, 1998].

[75] Our analysis of the reconstructed CS circulation patterns reveals a set of specific features of the CS circulation for these years:

1. The dominance of the northward flow of Pacific water into the Arctic Ocean between the Herald Shoal and Cape Lisburne.

2. The occasional reversal of the Bering Strait flow due to strong north and northeast winds. 


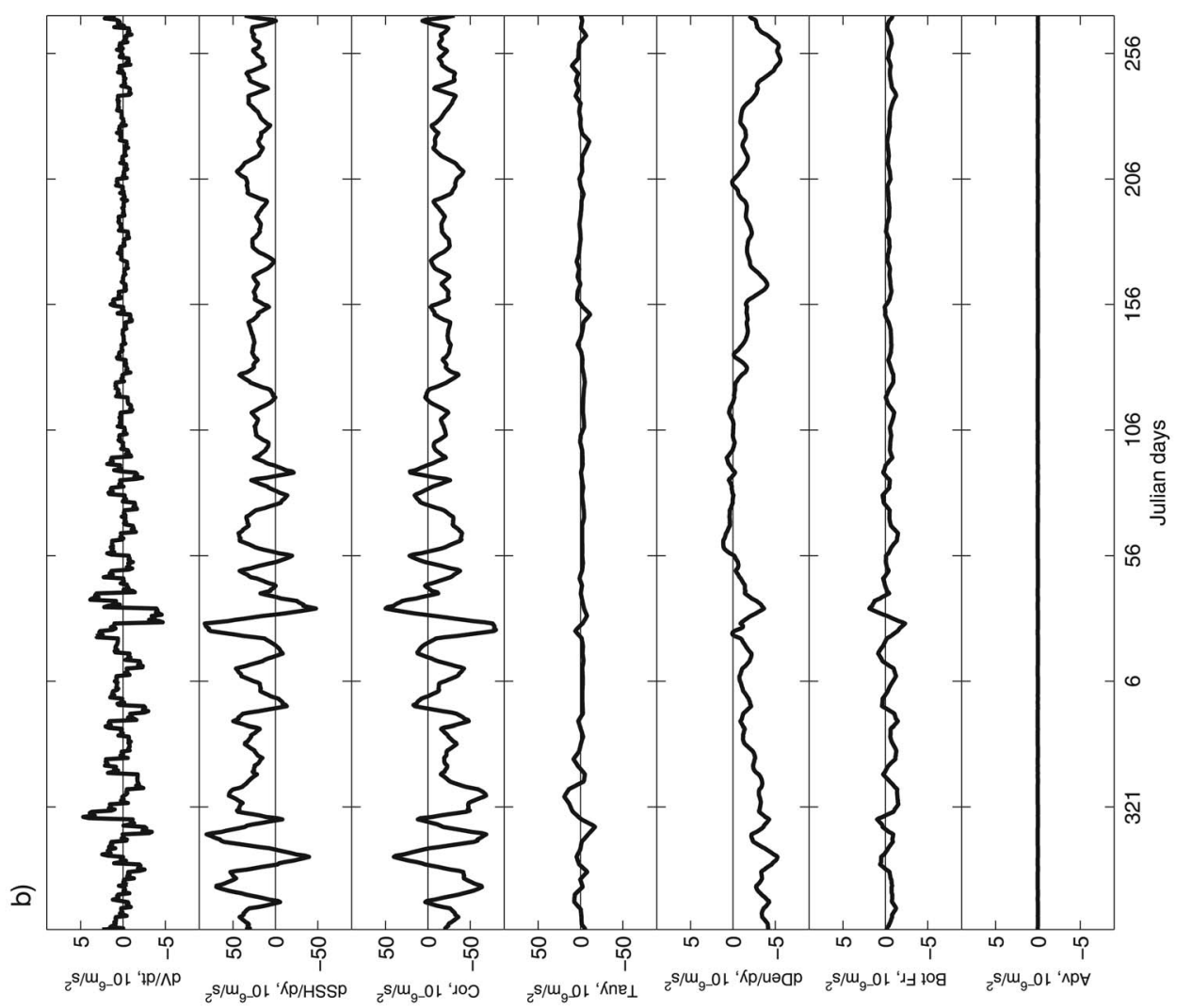

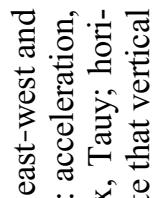

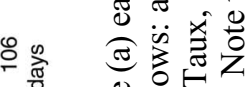

해웡

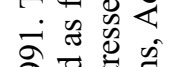

ลे 己ّ

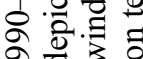

$-20.9$

类若

ㅎำ

类

卷春茫

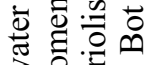

के छे

U \&

E 출

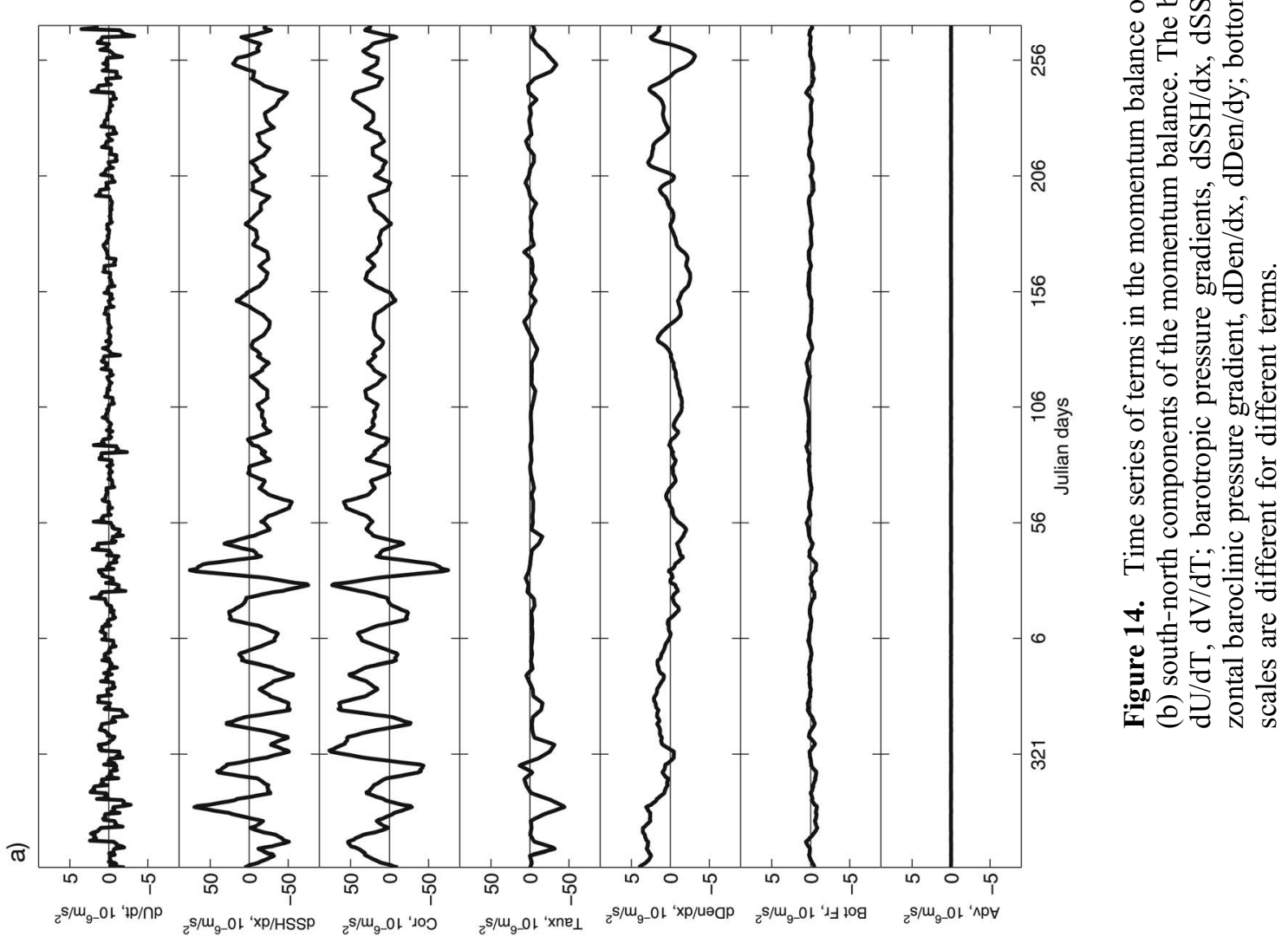




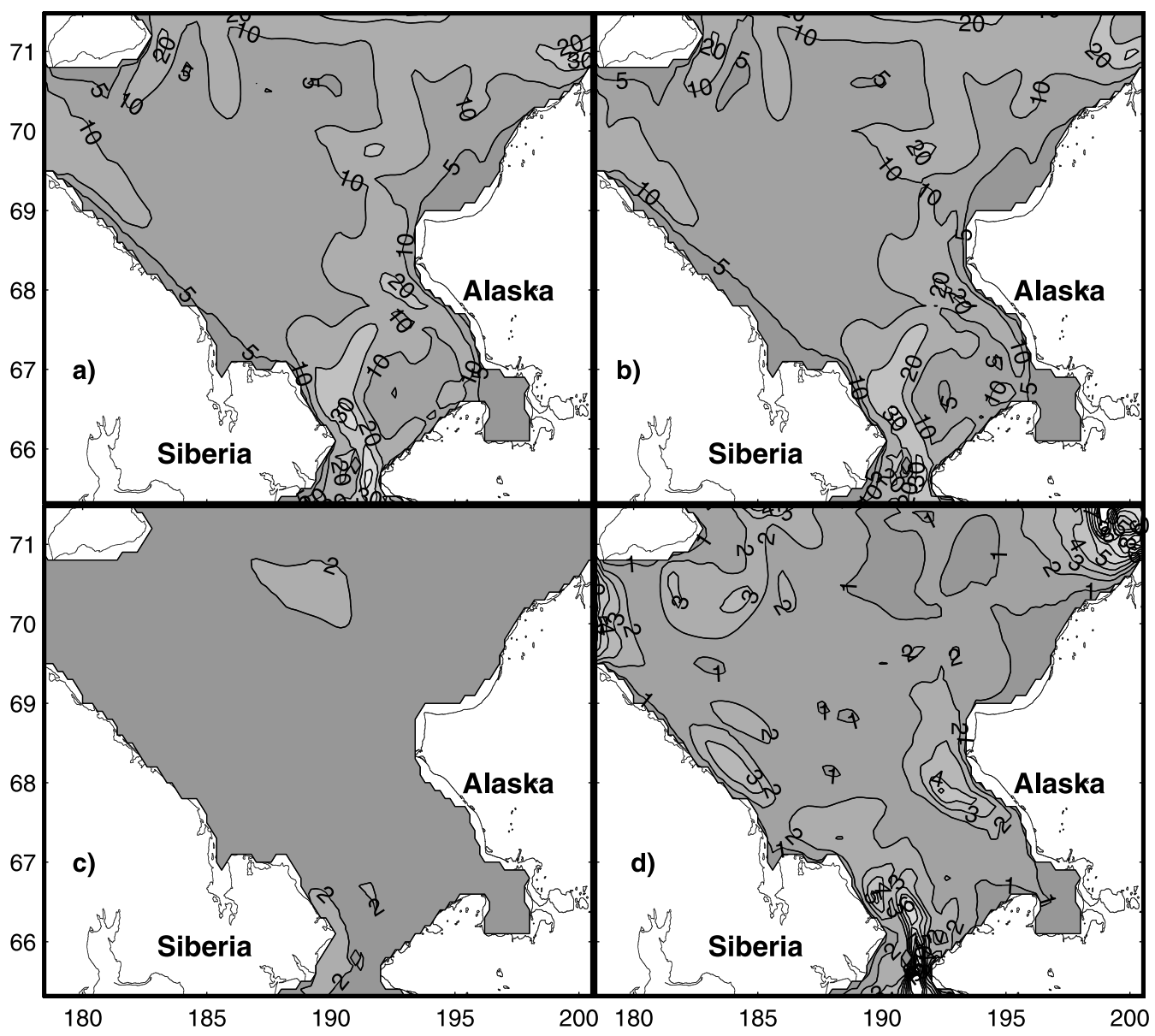

Figure 15. Spatial distribution of the annual mean amplitude of momentum balance terms (in $10^{-6} \mathrm{~m} \mathrm{~s}^{-2}$ ). (a) The distribution of the amplitude of the Coriolis term. (b) Amplitude of barotropic horizontal pressure gradient. (c) Amplitude of the horizontal baroclinic pressure gradient. (d) Amplitude of the surface stress term.

3. The occasional westward flow of the Siberian Coastal Current along the CS and Siberian coasts and anticyclonic circulation around Wrangel Island.

[76] Some of these features were observed and described previously for other years and periods [e.g., Weingartner et al., 1998; Münchow et al., 1999; Woodgate et al., 2005a], based on the analysis of observational data from moorings, drifters, and ship-mounted ADCPs. However, our approach in the current paper allowed us to analyze circulation patterns and changes in the entire dynamical system where roles of different factors can be assessed and causality of changes quantified. Below we summarize our major findings:

\subsection{Bering Strait Inflow}

[77] A detailed analysis of the reconstructed ocean state reveals that occasionally the summer increase of southward winds does not always result in a decrease of the Bering Strait transport. Analysis of the momentum balance suggests that baroclinic forcing could be responsible for this phenomenon. Therefore, including realistic T\&S fields in statistical models utilized for prediction of the Bering Strait transport [e.g., Roach et al., 1995] should improve the prediction of the Bering Strait transport during the summer season. Our approach provides quantification of the trans- port through the Bering Strait and along the pathways of Pacific water in the CS. Interestingly, the obtained estimates of the Bering Strait transport differ from estimates based on velocity observations on one mooring, but our results are in very good agreement with modeling results of Clement et al. [2005], based on the multidecadal simulation with a PanArctic numerical model. However, the spatial resolution of both models $(10 \mathrm{~km})$ is still not sufficient to resolve the relatively narrow Bering Strait; the recently deployed highresolution mooring array should resolve the issue.

\subsection{Long Strait Circulation}

[78] We found that the mean annual transport through Long Strait was only $0.01 \mathrm{~Sv}$. On the basis of one deployed mooring [Woodgate et al., 2005c], we estimate the outflow through Long Strait at $0.1 \mathrm{~Sv}$ but note that this may be balanced in volume by the southward flowing SCC. Our results support this assumption. It is important that the currents in Long Strait reconstructed by the 4D-var approach not only reflect the local observations but also take into account nonlinear constraints and conservation lows defined by the utilized ocean model. Despite a small mean transport, the net flow through Long Strait varies significantly, and transports can be up to $1 \mathrm{~Sv}$ in either direction. 


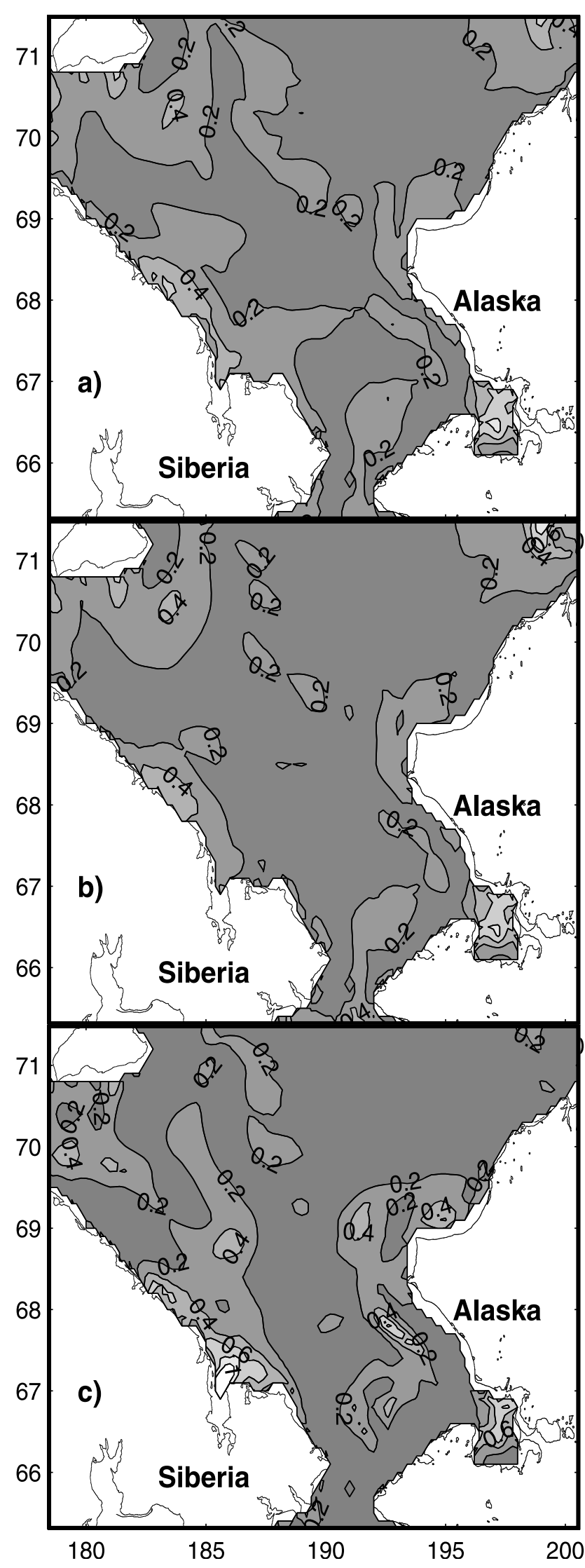

Intense flow events (Figure 7) in Long Strait in 1990-1991 occurred in late fall and early winter, while in spring and summer the total flow through Long Strait remained weak.

\subsection{Heat and Salt Transports}

[79] The obtained heat and freshwater transports in 19901991 are close to the estimates of Woodgate et al. [2005a]. However, both the observational and model-based numbers should be treated with caution for at least two reasons. First, there is an absence of real observations near the surface after November 1990. Thus, vertical stratification is practically defined by the climatologic background fields and our vertical mixing scheme but not by real T\&S observations. Second, the ocean model (SIOM) does not describe sea ice dynamics. Instead, it assimilates the heat/salt fluxes between the ice and ocean taken from the PIOMAS model. We speculate that the PIOMAS ice-ocean fluxes are more reasonable than the equivalent NCEP/NCAR data, but they still may differ significantly from the reality because the PIOMAS model assimilates only ice data and is not adjusted to oceanic observations.

\subsection{Residence Time of Pacific Water in the Chukchi Sea}

[80] Using modeled Lagrangian particles, we found that the residence time of Pacific water in the CS ranges between 150 and 260 days for the particles entering the CS in September and December 1990. This is in reasonable agreement with a very simplistic estimate made by Woodgate et al. [2005c]. Taking into account relatively high and persistent northern flow through the Bering Strait in July and August (Figure 7a), the residence time of Pacific water can be even shorter (approximately 100-120 days). Unfortunately, we do not have observations after September 1991 and cannot investigate this process accurately.

\subsection{Role of Different Factors in Chukchi Sea Dynamics}

[81] The analysis of the momentum balance allows us to quantify the relative impact of different dynamical processes in the CS. Our results do not differ significantly from the work of Spaulding et al. [1987] but reflect dynamics enforced by the assimilated data. In addition, our results provide observationally consistent estimates of the baroclinic terms, while results of Spaulding et al. [1987] are based on a barotropic model. We identified several regions where the baroclinic effects are important. Interestingly, the geographical location of these regions is very close to the regions with intensive coastal freshwater flows (Alaskan Coastal Current, Siberian Coastal Current) and/or polynyas near Cape Lisburne and the Siberian coast, where strong salinification and convection might impact the baroclinic terms in the momentum balance.

\subsection{Concluding Remarks}

[82] It is not surprising that a significant portion of our results agrees well with Woodgate et al. [2005a]. This is

Figure 16. Time-averaged fields representing the ratio of the amplitude of the horizontal baroclinic pressure gradient and the Coriolis term amplitude. Fields are averaged over (a) 1 year time period, (b) summer and fall period, (c) and winter time period. 
because both studies utilized essentially the same observations from moorings and hydrographic observations. We think that the combined analysis of all available ocean, sea ice, and atmospheric data allowed us to reproduce dynamically consistent patterns of the CS currents and to quantify important features of the circulation in 1990-1991.

[83] We also conclude that our study demonstrates that the 4D-var data processing technique is a useful tool for the analysis of in situ observations because of its extreme flexibility and ability to accumulate information from different sources and for its ability to fill data gaps with dynamically consistent solutions.

[84] It is also important to note that the employed approach has some weaknesses. One problem is the absence of a sea ice component in the SIOM data assimilation system. Instead, we assimilated sea ice data into the PIOMAS, a model that does not include assimilation of oceanic and atmospheric data. This approach resulted from significant problems with the development of conventional 4D-var data assimilation into the strongly nonlinear sea ice model.

[85] To address this issue, we plan to apply a recently developed reduced space ensemble 4D-var data assimilation algorithm [Yaremchuk et al., 2009] for the ice model and couple it with our ocean model.

[86] Acknowledgments. Panteleev, Proshutinsky, Nechaev, and Zhang were supported by the NSF ARC-0632154 award. Panteleev was also partially funded by JAMSTEC, Japan, the International Arctic Research Center, and a project funded by the North Pacific Research Board. Woodgate was supported by NSF awards ARC-0632154 and ARC-0531026.

\section{References}

Aagaard, K., and E. C. Carmack (1989), The role of sea ice and other fresh water in the arctic circulation, J. Geophys. Res., 94(C10), 14,485-14,498, doi:10.1029/JC094iC10p14485.

Aagaard, K., J. D. Shumacher, and A. T. Roach (1985), On the wind-driven flow through Bering Strait, J. Geophys. Res., 90(C4), 7213-7221, doi: 10.1029/JC090iC04p07213.

Awaji, T., S. Masuda, Y. Ishikawa, N. Sugiura, T. Toyoda, and T. Nakamura (2003), State estimation of the North Pacific Ocean by a four-dimensional variational data assimilation experiment, J. Oceanogr., 59(6), 931-943, doi:10.1023/B:JOCE.0000009582.24737.6f.

Carmack, E. C., and D. C. Chapman (2003), Wind-driven shelf/basin exchange on an Arctic shelf: The joint roles of ice cover extent and shelf-break bathymetry, Geophys. Res. Lett., 30(14), 1778, doi:10.1029/ 2003GL017526.

Cavalieri, D., and S. Martin (1994), The contribution of Alaskan, Siberian, and Canadian coastal polynyas to the cold halocline layer of the Arctic Ocean, J. Geophys. Res., 99(C9), 18,343-18,362, doi:10.1029/ 94JC01169.

Clement, J. L., W. Maslowski, L. W. Cooper, J. M. Grebmeier, and W. Walczowski (2005), Ocean circulation and exchanges through the northern Bering Sea-1979-2001 model results, Deep Sea Res., Part II, 52, 3509-3540, doi:10.1016/j.dsr2.2005.09.010.

Coachman, L. K., and K. Aagaard (1966), On the water exchange through Bering Strait, Limnol. Oceanogr., 11, 44-59, doi:10.4319/1o.1966. 11.1.0044.

Coachman, L. K., K. Aagaard, and R. B. Trip (1975), Bering Strait: The Regional Physical Oceanography, 172 pp., Univ. of Washington Press, Seattle.

Fedorova, Z. P., and Z. S. Yankina (1963), Supply of Pacific Water through the northern Bering Strait, Trudy AANII, 3, 21-44.

Gudkovich, Z. M. (1961), Nature of Pacific current in the Bering Strait and causes of its intensity and seasonal variability, Okeanologiya, 1, 35-48.

Gudkovich, Z. M. (1962), On the nature of the Pacific current in Bering Strait and the causes of its seasonal variations, Deep Sea Res., 9, 507-510.

Hibler, W. D., III (1980), Modeling a variable thickness sea ice cover, Mon. Weather Rev., 108, 1943-1973, doi:10.1175/1520-0493(1980) 108<1943:MAVTSI $>2.0 . \mathrm{CO} ; 2$.
Ladd, C., and N. Bond (2002), Evaluation of the NCEP/NCAR reanalysis in the NE Pacific and at the Bering Sea, J. Geophys. Res., 107(C10), 3158, doi:10.1029/2001JC001157.

Le Dimet, F. X., and O. Talagrand (1986), Variational algorithms for analysis and assimilation of meteorological observations: Theoretical aspects, Tellus, 38A, 97-100, doi:10.1111/j.1600-0870.1986.tb00459.x.

Lindsay, R. W., and J. Zhang (2006), Assimilation of ice concentration in an ice-ocean model, J. Atmos. Oceanic Technol., 23, 742-749, doi:10.1175/JTECH1871.1.

Madec, G., P. Delecluse, M. Imbard, and C. Levy (1999), OPA8.1 Ocean General Circulation Model. Reference Manual, Note du Pole modelisation, Institute Pierre-Simon Laplace, 91 pp., IPSL, France.

Martin, S., R. Drucker, R. Kwok, and B. Holt (2004), Estimation of the thin ice thickness and heat flux for the Chukchi Sea Alaskan coast polynya from Special Sensor Microwave/Imager data, 1990-2001, J. Geophys. Res., 109, C10012, doi:10.1029/2004JC002428.

Münchow, A., T. Weingartner, and L. Cooper (1999), The summer hydrography and surface circulation of the East Siberian Shelf Sea, J. Phys. Oceanogr., 29, 2167-2182, doi:10.1175/1520-0485(1999)029<2167: TSHASC $>2.0 . \mathrm{CO} ; 2$.

Nechaev, D., G. Panteleev, and M. Yaremchuk (2005), Reconstruction of the circulation in the limited region with open boundaries: Circulation in the Tsushima Strait, Okeanologiya, 45(6), 805-828.

Nihoul, J. C. J., P. Adam, P. Brasseur, E. Deleersnijder, S. Djenidi, and J. Haus (1993), Three-dimensional general circulation model of the northern Bering Sea's summer ecohydrodynamics, Cont. Shelf Res., 13, 509-542, doi:10.1016/0278-4343(93)90093-D.

Nikiforov, Y. G., and A. O. Shpayher (1980), Features of the formation of hydrological regime large-scale variations in the Arctic Ocean, Gidrometeoizdat, Leningrad, 269 pp., (in Russian).

Overland, J. E., and A. T. Roach (1987), Northward flow in the Bering and Chukchi seas, J. Geophys. Res., 92(C7), 7097-7105.

Panteleev, G., D. Nechaev, and M. Ikeda (2006a), Reconstruction of summer Barents Sea circulation from climatologic data, Atmos. Ocean, 44, 111-132, doi:10.3137/ao 440201.

Panteleev, G., P. Stabeno, V. A. Luchin, D. Nechaev, and M. Ikeda (2006b), Summer transport estimates of the Kamchatka Current derived as a variational inverse of hydrophysical and surface drifter data, Geophys. Res. Lett., 33, L09609, doi:10.1029/2005GL024974.

Panteleev, G., M. Yaremchuk, and D. Nechaev (2009), Optimization of mooring observations in Northern Bering Sea, Dyn. Atmos. Oceans, $48,143-154$

Pavlov, V. K., L. A. Timokhov, G. A. Baskakov, M. Y. Kulakov, V. K. Kurazhov, P. V. Pavlov, S. V. Pivovarov, and V. V. Stanovoy (1996), Hydrometeorological regime of the Kara, Laptev and East-Siberian Seas, Tech. Memo. APL-UW TM 1-96, 179 pp., Appl., Phys. Lab., Univ. of Wash., Seattle.

Proshutinsky, A. (1986), Calculation surge fluctuations in the level and circulation of water of the Chukchi Sea, Meteorol. Gidrol., 1, 54-61.

Proshutinsky, A. Y., and M. A. Johnson (1997), Two circulation regimes of the wind-driven Arctic Ocean, J. Geophys. Res., 102(C6), 12,493-12,514.

Proshutinsky, A., T. Proshutinsky, and T. Weingartner (1995), Northern Sea route reconnaissance report: Climatology of environmental conditions affecting commercial navigation along the Northern Sea Route, 196 pp., U.S. Army Corps of Eng., Anchorage, Alaska.

Proshutinsky, A., et al. (2007), Sea level variability in the Arctic Ocean from AOMIP models, J. Geophys. Res., 112, C04S08, doi:10.1029/ $2006 \mathrm{JC} 003916$.

Roach, A. T., K. Aagaard, C. H. Pease, S. S. Salo, T. Weingartner, V. Pavlov, and M. Kulakov (1995), Direct measurements of transport and water properties through Bering Strait, J. Geophys. Res., 100(C9), 18,443-18,457, doi:10.1029/95JC01673.

Roache, P. J. (1998), Fundamentals of computational fluid dynamics, 648 pp., Hermosa Publishers, Albuquerque, N. M.

Rothrock, D. A. (1979), Modeling sea ice features and processes, J. Glaciol., 24, 359-376.

Serreze, M., A. Baretti, A. Slater, R. Woodgate, K. Aagaard, R. Lammers, M. Steel, R. Moritz, M. Meredith, and C. Lee (2006), The large-scale freshwater cycle of the Arctic, J. Geophys. Res., 111, C11010, doi:10.1029/2005JC003424.

Shtokman, V. B. (1957), Influence of wind on currents in the Bering Strait and causes of their high velocities and predominant northern direction, Trans. Inst. Okeanolog, Akad. Nauk SSSR, 25, 171-197.

Spall, M. (2007), Circulation and water mass transformation in a model of the Chukchi Sea, J. Geophys. Res., 112, C05025, doi:10.1029/ 2005JC003364.

Spaulding, M., T. Isaji, D. Mendelsohn, and A. C. Turner (1987), Numerical simulation of wind-driven flow through Bering Strait, J. Phys 
Oceanogr., 17, 1799-1816, doi:10.1175/1520-0485(1987)017<1799: NSOWDF $>2.0 . \mathrm{CO} ; 2$.

Stammer, D., C. Wunsch, R. Giering, C. Eckert, P. Heimbach, J. Marotzke, A. Adcroft, C. N. Hill, and J. Marshal (2002), Global circulation during 1992-1997, estimated from ocean observations and a general circulation model, J. Geophys. Res., 107(C9), 3118, doi:10.1029/2001JC000888.

Stigebrandt, A. (1984), The North Pacific - a global scale estuary, J. Phys. Oceanogr., 14, 464-470, doi:10.1175/1520-0485(1984)014<0464: TNPAGS $>2.0 . \mathrm{CO} ; 2$.

Sverdrup, H. U. (1929), The waters on the North-Siberian Shelf, The Norwegian North Polar Expedition in the "Maud" 1918-1925, Scientific Results, vol. 4, 131 pp., Geofys. Inst., Bergen, Norway.

Thompson, D. W. J., and J. M. Wallace (1998), The Arctic Oscillation signature in the wintertime geopotential height and temperature fields, Geophys. Res. Lett., 25(9), 1297-1300, doi:10.1029/98GL00950.

Thorndike, A. S., D. S. Rothrock, G. A. Maykut, and R. Colony (1975), The thickness distribution of sea ice, J. Geophys. Res., 80(33), 4501-4513, doi:10.1029/JC080i033p04501.

Weingartner, T. J., D. J. Cavalieri, K. Aagaard, and Y. Sasaki (1998), Circulation, dense water formation and outflow on the northeast Chukchi Sea shelf, J. Geophys. Res., 103(C4), 7647-7662.

Weingartner, T. J., S. Danielson, Y. Sasaki, V. Pavlov, and M. Kulakov (1999), The Siberian Coastal Current: A wind- and buoyancy-forced Arctic coastal current, J. Geophys. Res., 104(C12), 29,697-29,713, doi:10.1029/1999JC900161.

Weingartner, T. J., K. Aagaard, R. Woodgate, S. Danielson, Y. Sasaki, and D. Cavalieri (2005), Circulation on the north central Chukchi Sea shelf, Deep Sea Res., Part II, 52, 3150-3174, doi:10.1016/j.dsr2.2005.10.015.

Winsor, P., and D. C. Chapman (2004), Pathways of Pacific water across the Chukchi Sea: A numerical model study, J. Geophys. Res., 109 C03002, doi:10.1029/2003JC001962.

Woodgate, R. A. (2003), Alpha Helix HX274 Cruise Report, Bering Strait Mooring Cruise June-July 2003, available at hpsc.apl.washington.edu/ AlphaHelix2003.html.

Woodgate, R. A., and K. Aagaard (2005), Revising the Bering Strait Freshwater flux into the Arctic Ocean, Geophys. Res. Lett., 32, L02602, doi:10.1029/2004GL021747.

Woodgate, R. A., K. Aagaard, and T. Weingartner (2005a), Monthly temperature, salinity, and transport variability of the Bering Strait through flow, Geophys. Res. Lett., 32, L04601, doi:10.1029/2004GL021880.

Woodgate, R. A., K. Aagaard, and T. Weingartner (2005b), A year in the Physical Oceanography of the Chukchi Sea. Moored measurements from autumn 1990-1991, Deep Sea Res., Part II, 52, 3116-3149, doi:10.1016/j.dsr2.2005.10.016.
Woodgate, R. A., K. Aagaard, J. H. Swift, K. K. Falkner, and W. M. Smethie Jr. (2005c), Pacific ventilation of the Arctic Ocean's lower halocline by upwelling and diapycnal mixing over the continental margin, Geophys. Res. Lett., 32, L18609, doi:10.1029/2005GL023999.

Woodgate, R. A., K. Aagaard, and T. J. Weingartner (2006), Interannual changes in the Bering Strait fluxes of volume, heat and freshwater between 1991 and 2004, Geophys. Res. Lett., 33, L15609, doi:10.1029/ 2006GL026931.

Wunsch, C. (1996), The Ocean Circulation Inverse Problem, 442 pp., Cambridge Univ. Press, Cambridge.

Yaremchuk, M., D. Nechaev, and G. Panteleev (2009), A method of successive corrections of the control subspace in the reduced-order variational data assimilation, Mon. Weather Rev., doi:10.1175/2009MWR2592.1

Zhang, J. (2005), Warming of the arctic ice-ocean system is faster than the global average since the 1960s, Geophys. Res. Lett., 32, L19602, doi:10.1029/2005GL024216.

Zhang, J., and W. D. Hibler (1997), On an efficient numerical method for modeling sea ice dynamics, J. Geophys. Res., 102(C4), 8691-8702, doi:10.1029/96JC03744.

Zhang, J., and D. A. Rothrock (2001), A thickness and enthalpy distribution sea ice model, J. Phys. Oceanogr., 31, 2986-3001, doi:10.1175/ 1520-0485(2001)031<2986:ATAEDS $>2.0 . \mathrm{CO} ; 2$.

Zhang, J., and D. A. Rothrock (2003), Modeling global sea ice with a thickness and enthalpy distribution model in generalized curvilinear coordinates, Mon. Weather Rev., 131(5), 681-697, doi:10.1175/15200493(2003)131<0845:MGSIWA $>2.0$. CO;2.

Zhang, J., and D. A. Rothrock (2005), The effect of sea ice rheology in numerical investigations of climate, J. Geophys. Res., 110 , C08014, doi:10.1029/2004JC002599.

D. A. Nechaev, Department of Marine Science, University of Southern Mississippi, Stennis Space Center, 118 College Dr., Hattiesburg, MS 39406-0001, USA.

G. Panteleev, International Arctic Research Center, University of Alaska Fairbanks, 505 South Chandalar Dr., PO Box 757500, Fairbanks, AK 99775, USA. (gleb@iarc.uaf.edu)

A. Proshutinsky, Woods Hole Oceanographic Institution, 86 Water St., Woods Hole, MA 02543-1052, USA.

R. Woodgate and J. Zhang, Applied Physics Laboratory, University of Washington, 1013 NE 40th St., Box 355640, Seattle, WA 98105-6698, USA. 